\title{
Active Carbon-Based Nanomaterials in Food Packaging
}

\author{
Katarzyna Mitura 1,2,* Joanna Kornacka ${ }^{2}$, Elżbieta Kopczyńska ${ }^{2}$, Jacek Kalisz ${ }^{2}$, Ewa Czerwińska ${ }^{2}$, \\ Maciej Affeltowicz ${ }^{2}$, Witold Kaczorowski ${ }^{3}{ }^{\circledR}$, Beata Kolesińska ${ }^{4}{ }^{\circledR}$, Justyna Frączyk ${ }^{4}$, Totka Bakalova ${ }^{1}(\mathbb{D}$, \\ Lucie Svobodová ${ }^{1}$ and Petr Louda ${ }^{1}$ (1)
}

1 Faculty of Mechanical Engineering, Technical University of Liberec, 46117 Liberec, Czech Republic; totka.bakalova@tul.cz (T.B.); lucie.svobodova@tul.cz (L.S.); petr.louda@tul.cz (P.L.)

2 Faculty of Mechanical Engineering, Koszalin University of Technology, Śniadeckich 2, 75-453 Koszalin, Poland; joanna774@tlen.pl (J.K.); ela.kopczynska17@gmail.com (E.K.); jacekl300@gmail.com (J.K.); ewa.czerwinska@tu.koszalin.pl (E.C.); maciej.affeltowicz@gmail.com (M.A.)

3 Faculty of Mechanical Engineering, Institute of Material Sciences and Engineering, Lodz University of Technology, Stefanowskiego 1/15, 94-924 Lodz, Poland; witold.kaczorowski@p.lodz.pl

4 Faculty of Chemistry, Institute of Organic Chemistry, Lodz University of Technology, Żeromskiego 116, 90-924 Lodz, Poland; beata.kolesinska@p.lodz.pl (B.K.); justyna.fraczyk@p.lodz.pl (J.F.)

* Correspondence: katarzyna.mitura@tu.koszalin.pl

check for updates

Citation: Mitura, K.; Kornacka, J.; Kopczyńska, E.; Kalisz, J.;

Czerwińska, E.; Affeltowicz, M.;

Kaczorowski, W.; Kolesińska, B.;

Frączyk, J.; Bakalova, T.; et al. Active Carbon-Based Nanomaterials in Food Packaging. Coatings 2021, 11, 161. https://doi.org/10.3390/

coatings11020161

Academic Editors: Stefano Farris and Jaejoon Han

Received: 6 December 2020

Accepted: 26 January 2021

Published: 29 January 2021

Publisher's Note: MDPI stays neutral with regard to jurisdictional claims in published maps and institutional affiliations.

Copyright: (c) 2021 by the authors. Licensee MDPI, Basel, Switzerland. This article is an open access article distributed under the terms and conditions of the Creative Commons Attribution (CC BY) license (https:/ / creativecommons.org/licenses/by/ $4.0 /)$.

\begin{abstract}
Carbon-based nanomaterials (CBN) are currently used in many biomedical applications. The research includes optimization of single grain size and conglomerates of pure detonated nanodiamond (DND), modified nanodiamond particles and graphene oxide (GO) in order to compare their bactericidal activity against food pathogens. Measurement of grain size and zeta potential was performed using the Dynamic Light Scattering (DLS) method. Surface morphology was evaluated using a Scanning Electron Microscope (SEM) and confocal microscope. X-ray diffraction (XRD) was performed in order to confirm the crystallographic structure of detonation nanodiamond particles. Bacteriostatic tests were performed by evaluating the inhibition zone of pathogens in the presence of carbon based nanomaterials. Raman spectroscopy showed differences between the content of the diamond and graphite phases in diamond nanoparticles. Fluorescence microscopy and adenosine- $5^{\prime}$-triphosphate (ATP) determination methods were used to assess the bactericidal of bioactive polymers obtained by modification of food wrapping film using various carbon-based nanomaterials. The results indicate differences in the sizes of individual grains and conglomerates of carbon nanomaterials within the same carbon allotropes depending on surface modification. The bactericidal properties depend on the allotropic form of carbon and the type of surface modification. Depending on the grain size of carbon-based materials, surface modification, the content of the diamond and graphite phases, surface of carbon-based nanomaterials film formation shows more or less intense bactericidal properties and differentiated adhesion of bacterial biofilms to food films modified with carbon nanostructures.
\end{abstract}

Keywords: DLS method; functionalized carbon-based nanomaterials (CBNs); detonation nanodiamond particles (DND); graphene oxide (GO) film; carbon-based nanomaterials film formation; bactericidal properties; adhesion tests

\section{Introduction}

Carbon-based nanomaterials are a very differentiated group covering allotropic forms with a distinct crystallographic structure. Particularly interesting materials are powders and nanopowders, because they have a developed surface with the possibility of chemical and plasma-chemical functionalization of their surfaces [1-5]. Finally, it is possible to obtain films and laminates with modified carbon nanostructures that have controlled surface activity for packaging fat-containing products [2-4,6-8]. Different allotropic forms of carbon (diamond, graphite, carbine) and various forms of carbon (graphene, nanotubes, fullerenes) influence the colonization and biological activity of foodborne pathogens on 
chicken embryo development, including angiogenesis. Depending on the allotropic forms of carbon which are determined by the crystallographic structure based on the hybridization of carbon atoms, it is possible to observe the high biological activity of nanodiamonds in inactivating food-borne pathogens without cytotoxic activity damaging the fluidity of the cell membrane, and without mutagenic effects on the cell nucleus and genetic material. The graphene family materials are cytotoxic and destructive to the structure of the cell membrane, especially graphene oxide (GO) which has a high oxidoreductive potential, resulting in damage to cell membranes in the process of lipid peroxidation and intensification of oxidative stress in bacteria, fungi and other cells. From this point of view, it seems that the use of diamond nanoparticles added to food packaging is safe and does not carry the risk of migration of cytotoxic substances into food. This can be compared with the use of silver nanoparticles in food preservation devices, which proved to be a not very effective and safe solution due to the presence of metal nanoparticles, which can have toxic effects on the human body. However, the use of external barrier graphene layers with antimicrobial properties may be a potential use for graphene in the packaging industry $[2,4,5,9-14]$.

Analysis of the current food and cosmetic markets is focused on identifying food borne pathogen. Food preservation is the most interesting aspect from the perspective of possible applications, e.g., carbon-based materials for the production of bioactive products with nanodiamonds and barriers with graphene family materials in food packaging. Additionally intelligent food packaging can be used to indicate whether or not the food is safe for consumption. The development of active packaging containing carbon nanostructures for packaging food and cosmetics with antioxidant properties significantly reduces their rancidity. In addition, carbon-based nanomaterials, and in particular nanodiamonds are biomarkers and natural biosensors that can create a sensitive and specific system for detecting food-borne pathogens. Incorporation on the surface DND fluorophore leads to material with photovoltaic stability, long fluorescence times (10 ns) and a lack of cytotoxicity $[3-6,8,15-26]$.

Several research reports have proved that nanomaterials can be used to protect food and ultimately extend shelf-life. It is very important to design and study nanotoxicity and ecotoxicity in the design of active and protective food packaging and also the migration of bioactive substances to food products. In addition to the impact of extending the shelflife, the potential antimicrobial activity of intelligent food packaging has become a basic condition for modern food packaging $[27,28]$. The basic element of manufacturing active food packaging is to add antimicrobial properties by introducing antibacterial agents into the packaging systems. Possible methods of achieving this include biodegradable polymer films incorporating antimicrobial agents. All these elements are to ensure the production of antibacterial active food packaging based on the controlled release of antimicrobial factors, safe and non-toxic to human health [29]. One of the most important elements is the application of nanostructures for "smart food packaging" as nanobiosensors for the detection of food borne pathogens by silver, gold, magnetic nanoparticles, immunomagnetic liposome nanoparticles, aptamer conjugated gold nanoparticles, liposome nanoparticles quantum dots, and carbon nanotubes [30].

Figure 1 shows important applications of nanomaterials, including nanoparticles in the food sector. Nanoparticles, due to their developed surface, are used in the field of active, intelligent nano-packaging for food as they are ecological, non-toxic, anti-allergic, barrier-related, e.g., for heavy metals, so-called: functional food packages which are biosensor/sensitive to environmental, bacterial and toxic contaminants originating from compounds of stale food [30]. 


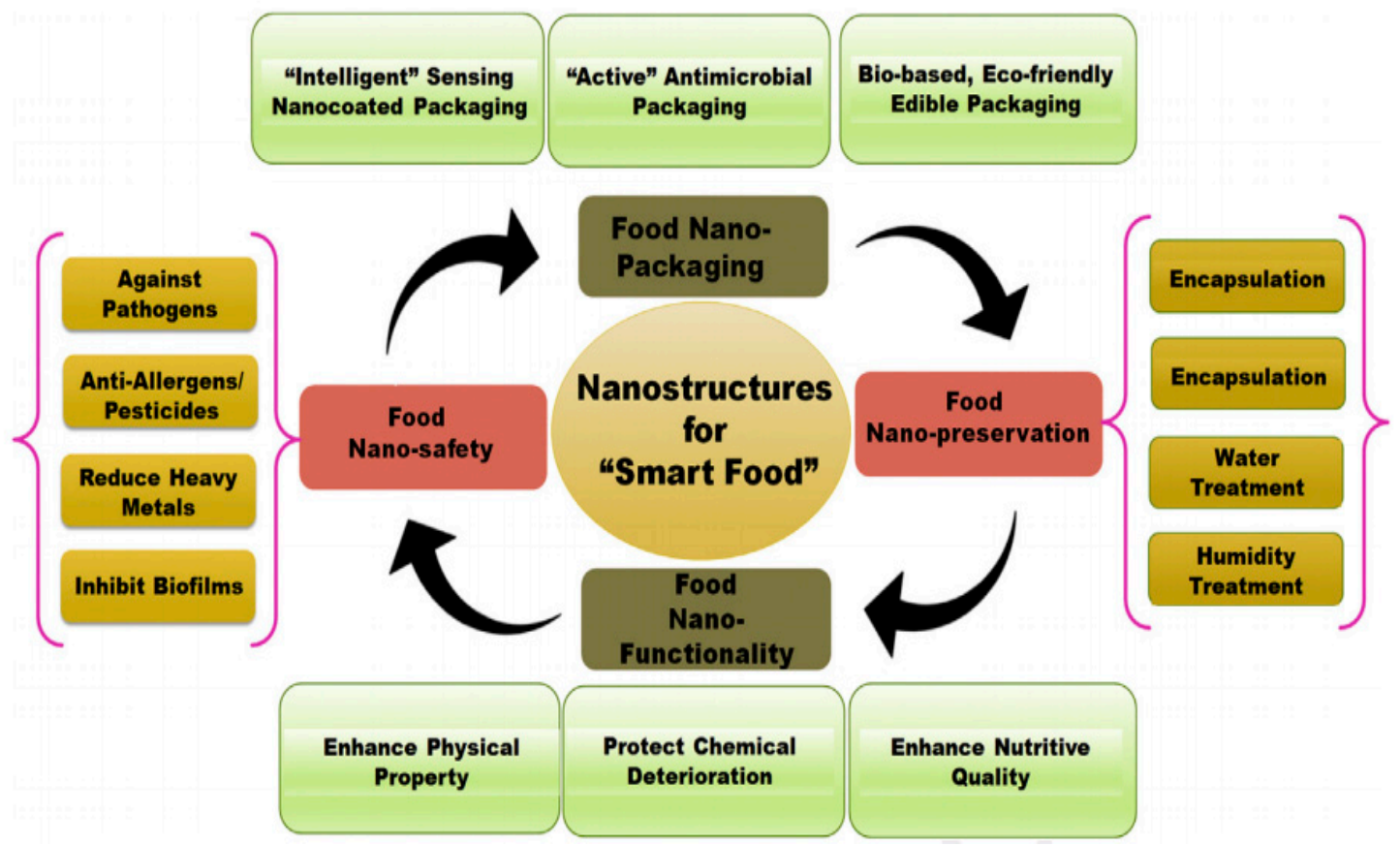

Figure 1. Systematic representation of application of nanoparticles in various areas of food industry. Reprinted with permission from [30]. Copyright 2018 Elsevier.

Food protection can be monitored by the use of intelligent packaging using indicators that assess the degree of suitability for consumption and the degree of damage. These can be chemical, gas sensors, biosensors and thermal indicators, leak indicators, freshness indicators, $\mathrm{pH}$ indicators and radio frequency identification tags [31]. "Food Contact Materials" (FCMs) are defined as materials that have contact with food. They ensure thermal stability and protect against bacterial contamination. e.g., nanoparticles added to agar protect against persistent bacterial infections [32]. Biological and chemical sampling are emerging topics in nanotechnology for food packaging and the food industry. The use of microfluidic devices for DNA analysis of pathogens is modern and future-proof and allows the possibility of analyzing food-borne pathogens which directly affects progress in the use of active food packaging. [33,34].

Carbon-based nanoparticles are characterized by lower toxicity compared with metal nanoparticles, quantum dots, silica based Cornell dots, and lipid and polymer based nanoparticles which have a negative impact on the skin, respiratory tract, digestive system, blood-brain barrier, as well as induction of the inflammatory process and oxidative stress caused by free radicals $[35,36]$. The migration of nanoparticles from packaging to food products may have toxic potential in the human body and the environment [37]. Nanostructured materials, such as starch based films modified by silver nanoparticles can be used in contact with food, because the results of contact tests with the pathogens $C$. albicans, E.coli and S. aureus do not reveal microbial transmission [38-40]. The tendency to create interaction spaces mainly results in very aggressive food borne pathogens, like for example L. monocytygenes, P. aeruginosa, and/or S. aureus., L. monocytygenes which form with L. plantarum on mixed biofilms which are resistant to disinfectants. Therefore, the control of bacterial persistence on biofilms on the food and the design of bioactive food packaging is now an overarching goal in the food sector [41]. Many antibacterial agents are known for food protection. The antibacterial activity of metal nanostructures is dependent on their large surface area, size, shape and chemical functionalization. The most important mechanism of bacterial toxicity is the damage to the fluidity of the cell membrane and the induction of oxidative stress in cells resulting from damage and degradation. Food packaging based on nanocomposites has been shown to inhibit bacterial growth on fungi. The development of engineered nanomaterials (ENM) for food packaging confirms the benefits 
of modifying polymers and other nanomaterials to give them properties of antibacterial control and to allow for the migration of active, non-toxic substances from packaging to food [42-48]. Some research points to their antibacterial properties and ability to interfere in biofilm formation. Moreover, the results showed a stronger antibacterial activity of negatively charged nanodiamonds particles against Escherichia coli and Bacillus subtilis compared to positively charged nanodiamonds. The same studies showed, that nanodiamond structures lose their antibacterial properties after contact with biomolecules from nutrition media, most likely due to unspecific reactions with media biomolecules $[49,50]$. The nanodiamonds have a lot of interesting advantages, for example, hight stability in corrosion media, chemically inert, optically transparent and biocompatibility. Several publications proved that the nanodiamonds do not induce significant cytotoxicity in a variety of animal/human cell types [51,52], respectively in primary culture of endothelial cells [53] but might be more toxic for microorganisms [49]. At the molecular level, nanodiamond particles inhibit the gene expression responsible for oxidative stress and carcinogenesis [54] and they induce apoptosis in human endothelial cells [55]. A positive effect of diamond nanoparticles in contact with the dental tissue is also observed [56]. The toxicity of carbonbased nanomaterials, mainly graphene, carbon nanotubes and fullerenes on human and animal cells, and antibacterial activity are widely commented on in the literature. The toxicity of carbon-based nanomaterials, mainly graphene and fullerenes on human and animal cells, and antibacterial activity are widely commented on in the literature [57]. Diamond nanoparticles that do not show cytotoxicity can be used in regenerative medicine and tissue engineering as nano-scaffolds. Most often it concerns multifunctional bone nanoscaffolds consisting of biopolymers modified with diamond nanoparticles which have no cytotoxic effect on osteoblasts and do not disturb with proliferation of these cells $[53,58,59]$. Nanodiamond nanoparticles compared to carbon black and carbon nanotubes show the smallest cytotoxic effect on cell lines including the line of tumor cells [60].

The aim of this study was to modify food packaging materials by using selected carbon-based nanomaterials (CBNs) expecting that the modified packaging materials will have an antibacterial effect, which should affect the durability and safety of food. Before starting the research on the effect of modified packaging materials on selected bacterial strains, it was assumed that it would be important to assess the size of individual grains and conglomerates of used selected carbon-based nanomaterials, as well as bactericidal activity against selected pathogens. It was planned to use pure detonated nanodiamond (DND), and various modified nanodiamond materials. It was expected that the use of variously modified materials based on nanodiamonds would allow understanding and systematize the relationship between their chemical structure and antibacterial activity. Additionally, in the study it was also planned to use graphene oxide (GO) in order to compare materials of different structures. Measurement of grain size and zeta potential was performed using the Dynamic Light Scattering method. Surface morphology was evaluated using Scanning Electron Microscope (SEM), while the share of D and G content in the applied carbon nanomaterials was determined by Raman spectroscopy, with the expectation that it would be possible to determine the impact of the ID/IG ratio on the antibacterial activity of nanomaterials. Modified by using various carbon-based nanomaterials food packaging films have been tested for their colonization by pathogens, which can be referred to as an antibacterial effect. It was expected that the conducted research would reveal rules enabling the design of new, nanoparticle-modified packaging materials for various food products, protecting food against both Gram-positive and Gram-negative bacteria.

\section{Materials and Methods}

2.1. Carbon-Based Nanomaterials

In this work the following materials were used:

- $\quad$ graphene oxide (GO);

- amorphous carbon powder formed using Radio Frequency Plasma Activated Chemical Vapor Deposition Method (RF); 
- $\quad$ rhodamine modified detonated nanodiamond (MDCHF);

- plasma-chemically modified detonated nanodiamond (MDP1);

- chemically modified detonated nanodiamond particles with hydroxyl functional groups (MDCHPOH);

- $\quad$ non-modified pure detonated nanodiamond particles (DND).

Pure detonation nanodiamond particles (DND) were manufactured by the Danilenko method and a single grain size was estimated at about 2-4 $\mathrm{nm}$ [1]. The single grain size specification of the individual particles provided by the Adamas Nanotechnologies Company range from 2 to $4 \mathrm{~nm}$. The commercial graphene oxide (GO) tested was in the form of a $1 \%$ water suspension, FL-GO, from the NANOMATERIALS Leszek Stobiński Company (Warsaw, Poland), in which graphene flakes form a film.

\section{Preparation of Rhodamine Modified Detonated Nanodiamond (MDCHF)}

The starting material was pure detonated nanodiamond (DND) manufactured by the Danilenko method. In the first stage DND was subjected to modification aimed at introducing hydroxyl groups on the surface of nanomaterials. The standard Fenton reaction procedure for modification of DND particles was used for the preliminary functionalization [61]. In the next step, the hydroxyl groups were esterified with Rhodamine B (Merck, Warsaw, Poland). Rhodamine B was activated by using 4-toluenosulphonate 4-(4,6dimethoxy-1,3,5-triazin-2-yl)-4-methylmorpholine (DMT/NMM/TosO ${ }^{-}$) [62]. The choice of DMT/NMM/ $\mathrm{TosO}^{-}$as a coupling reagent resulted from both its efficiency as a condensing reagent and to ease the removal of side products, thereby ensuring that there were no deposits on the functionalized nanomaterials [63,64]. Rhodamine B $(0.958 \mathrm{~g}, 2 \mathrm{mmol})$ was dissolved in a mixture of dimethylformamide (DMF) and water (9:1) $(10 \mathrm{~mL})$. After cooling the solution to $0{ }^{\circ} \mathrm{C}$, DMT/NMM/TosO ${ }^{-}(0.826 \mathrm{~g}, 2 \mathrm{mmol})$ and $\mathrm{N}$-methylmorpholine (NMM) $(110 \mu \mathrm{L}, 1 \mathrm{mmol})$ were added while stirring vigorously. Stirring was continued for $1 \mathrm{~h}$ until the reagent was consumed. After this time, nanodiamond powder with hydroxyl groups on the surface and NMM $(1100 \mu \mathrm{L}, 1 \mathrm{mmol})$ was added to the solution of Rhodamine B triazine ester. The suspension was stirred for $12 \mathrm{~h}$ at room temperature. The precipitate was filtered off under reduced pressure and washed with DMF $(10 \mathrm{~mL})$, water: DMF (1:1) $(10 \mathrm{~mL})$, and DMF $(10 \mathrm{~mL})$. Washing was continued until no reagents were found in the filtrate (TLC control). The residue was suspended in water $(10 \mathrm{~mL})$ and lyophilized.

\subsection{SEM Analysis}

Each sample was placed successively in the chamber on the stage, by means of which it was possible to set the appropriate position and angle of inclination. The chamber was deaerated for low vacuum (LV) testing. A scanning electron microscope (SEM), JSM-5500 LV, from Jeol Ltd. (Peabody, MA, USA) was used for this purpose.

\subsection{XRD Analysis}

XRD analysis was performed using an X'Pert Panalytical powder diffractometer (Malvern Panalytical, Malvern, UK). The measurement was carried out using a copper anode ( $\mathrm{CuK} \alpha$ radiation beam, $\lambda=1.5406 \AA$ ). The samples were scanned in Bragg-Brentano geometry in the $2 \theta$ angle range $10-100^{\circ}$ using a continuous rotation of the sample with a constant period of $\mathrm{T}=8 \mathrm{~s}$.

\subsection{Confocal Microscope Analysis}

Assessment of surface morphology on the investigated samples was performed on a SENSOFAR S neox confocal microscope). It is a microscope that allows non-contact scanning of surfaces using confocal and interferometric methods. Confocal microscopy was performed on the $S$ neox high-performance 3D optical profiler (Sensofar metrology, Barcelona, Spain) with EPI 20X v35 objective that allows non-contact optical 3D profiling. The neox uses a high-resolution charge-coupled sensor $(0.69 \mu \mathrm{m} / \mathrm{pixel})$ of up to $1360 \times 1024$ pixels (observed area $850.08 \mu \mathrm{m} \times 709.32 \mu \mathrm{m}$ ). The sample was affixed in 
such a way as to avoid the slightest movement during sensing (due to vibration, air flow, etc.). Confocal microscopy was also performed on the $\mathrm{S}$ neox high-performance 3D optical profiler (Sensofar metrology, Barcelona, Spain) with EPI 50X v35 objective that allows non-contact optical 3D profiling. The neox uses a high-resolution charge-coupled sensor $(0.28 \mu \mathrm{m} /$ pixel) of up to $1360 \times 1024$ pixels (observed area $340.03 \mu \mathrm{m} \times 283.73 \mu \mathrm{m})$. This sample was also affixed in such a way as to avoid the slightest movement during sensing (due to vibration, air flow, etc.).

\subsection{Dynamic Light Scattering (DLS) Analysis}

The Litesizer 500 Anton Paar is a device that allows the determination of particle size, zeta potential and molecular weight, by using dynamic light scattering. In our research, the parameters were set as follows: temperature $25^{\circ} \mathrm{C}$; solvent for powders-water (refractive index 1.3), refractive index for diamond: 2.42 and grapheme: 1.3; one measurement time: $10 \mathrm{~s}$; the optical system was set to automatic mode; the measurements were carried out in disposable measuring cuvettes. The sample should be used following filtration or centrifugation to remove dust and artifacts from the solution. All the data to be obtained during the test can be determined by two curves, one from the trace of particle intensity (number distribution) and the other from the volume distribution. DLS is a technique that is used to measure the size of a sample.

\subsection{Statistical Analysis}

Kalliope $^{\mathrm{TM}}$ is the simple analytical software used in Anton Paar's Litesizer ${ }^{\mathrm{TM}}$ particle analysers. Before proceeding with the particle analysis (DLS optimization), the correct solvent (water) for our purposes was selected and then the "start" button was pushed. The system automatically changes the gain, determines the optimal focal position and the best DLS detection angle. Experimentation, analysis and report generation takes place within seconds. With the help of MATLAB, the necessary calculations were able to be made and the graphs were produced.

\subsection{Raman Spectroscopy}

Raman studies were conducted on the Renishaw device in a Via Raman spectrometer. The spectra were analyzed in the Raman shift range 900 to $2000 \mathrm{~cm}^{-1}$ with an excitation wavelength of $532 \mathrm{~nm}$. Each spectrum was deconvoluted into two peaks (D and G) by using spectral analysis software (Peak Fit v4.11) to calculate the intensity ratio ID/IG.

\subsection{Antibacterial Test}

Tests were performed on standard strains of four bacteria: Escherichia coli ATCC 25922, Pseudomonas aeruginosa NCTC 12903/ ATCC 27853, Staphylococcus aureus ATCC ${ }^{\circledR} 25923$, Streptococcus mutans ATCC 35668. Assessment of antibacterial activity was made using the direct method based on the criteria contained in the description of SN 195920 [65]. The antimicrobial effect of carbon-based nanomaterials was assessed in accordance with the criteria contained in the description of the SN 195920-ASTM standard E2922 [53]. The surface of the medium was inoculated with the suspension of test microorganisms with a concentration of $10^{6} \mathrm{CFU} / \mathrm{mL}$ ( $0.5 \mathrm{Mc}$ Farland densitometer, DN 1B MF, BIOSAN, Riga, Latvia) and after $20 \mathrm{~min}$ the nanomaterials were placed in the incubator and incubated at $37^{\circ} \mathrm{C}$ for $24 \mathrm{~h}$. After incubation, the growth inhibition zones of the test subjects were evaluated for microorganisms. The criterion for assessing bactericidal properties is the presence and the size of the zone inhibiting the growth of the tested microorganisms. Research was carried out in triplicate for each sample tested and each test microorganism.

\subsection{Preparation of Food Films Modified with Carbon-Based Nanomaterials}

Different types of food laminates (monoplex, duplex, triplex, quadroplex were used for modification with carbon-based nanomaterials. Single-layer (monoplex) laminate for packing ice cream, two-layer (duplex) laminate for packing ketchup, three-layer (triplex) lami- 
nate for packing coffee, four-layer (quadroplex) laminate for packing mustard. Used packaging films are made of: polyethylene terephthalate (PET)/aluminium (ALU)/polyethylene (PE) (PET/ALU/PE) in the case of coffee packaging; PET/ALU/MET PET/PE in the case of Ketchup packaging, where MET PET is metalized polyethylene terephthalate; $\mathrm{PET} / \mathrm{ALU} / \mathrm{PE}$ in the case of mustard packaging; oriented polypropylene (OPP) in the case of ice cream packaging. Laminates differ in the number of layers-polymers.

Carbon-based nanomaterials powders were applied in two ways (Figure 2). Samples of food packaging film with dimensions of $10 \mathrm{~mm} \times 10 \mathrm{~mm}$ were treated with diamond nanopowders aerosol (a suspension consisting of nanopowders mixed with water) or an $1 \%$ aqueous suspension of graphene oxide. The concentration of diamond nanopowders aerosol was $1 \mathrm{mg} / 1 \mathrm{~mL}$ deionised water. The application of the diamond nanopowders aerosol was performed by means of a hand pump in the form of double application on each film. Graphene oxide was applied by hand with a wooden spatula in the form of biofilm. The application was carried out immediately after the solution was mixed in the ultrasonic device. The diamond nanoparticles suspension was sprayed on food films in a fog. The films with applied layers of diamond nanopowders or graphene oxide were then left to dry for $30 \mathrm{~min}$ at room temperature. There was obtained to potentially equal amounts of sprayed or applied product on the material, but this was not the primary role as the main phenomenon was how carbon powders interact with pathogens.

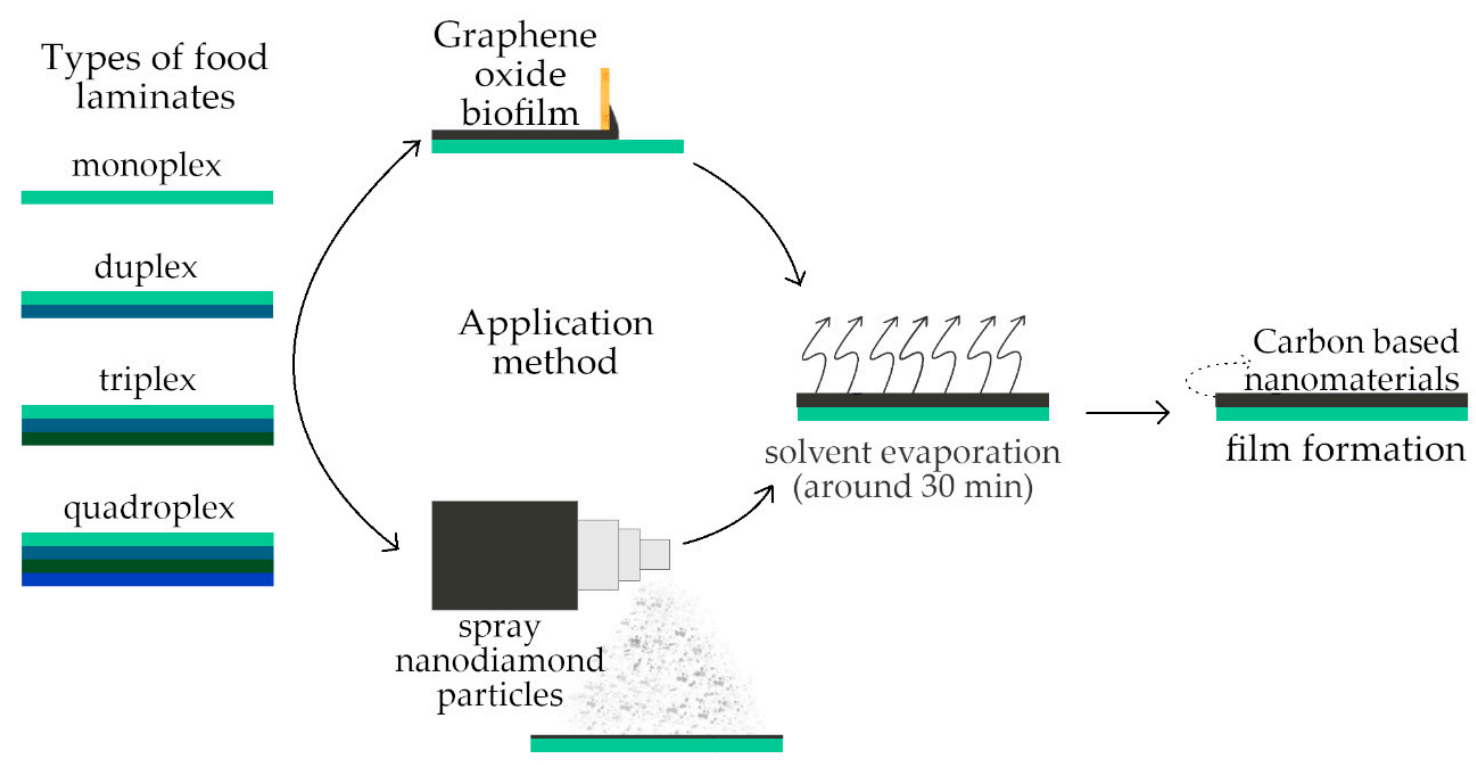

Figure 2. Schematic representation of the carbon based nanomaterials film formation.

\subsection{Adhesion Tests-Fluorescence Microscopy}

Microbial adhesion to polymer surfaces was studied using a fluorescence microscope equipped with a special MOTIC light kit consisting of a fluorescent lens used for epifluorescence and an M2 digital camera. The stained cells shown in the photos were counted using a special microscope program, which was also used to process and store the photos. After the incubation period, all cells and culture media that had not been adhered to films were removed from the polymers by washing them with sterile distilled water. The film was then coated with $0.5 \mathrm{~cm}^{3}$ bisbenzidine solution and incubated for $120 \mathrm{~s}$. Later, the samples were washed again with distilled water (dye removal), $0.3 \mathrm{~cm}^{3}$ of propidine iodide solution was applied, incubated (120 s), washed again. At the end the sample was dried with a gentle air stream, then the fluorescence of stained cells was observed at 100-fold magnification, with respect to cell viability-red (dead cells, stained with propidine iodide). Coloured bacterial cells were counted in 10 fields of view of the microscope. The viability of the bacteria was determined by using the cell culture method and ATP method, and the 
sum of living and dead cells that were subjected to adhesion was taken into account in the calculations. To calculate the number of cells per $1 \mathrm{~mm}^{2}$ of polymer surface, the image surface area was determined using a computer coupled with a fluorescence microscope (Figure 3). The adhesion measurements for different film types were performed three times using fluorescence microscopy. Four strains of bacteria were used for adhesion studies: Escherichia coli ATCC 25922, Pseudomonas aeruginosa NCTC 12903/ATCC 27853, Staphylococcus aureus ATCC ${ }^{\circledR}$ 25923, Streptococcus mutans ATCC 35668. The studies were performed on standard strains: Escherichia coli ATCC 25922, Pseudomonas aeruginosa NCTC 12903/ATCC 27853, Staphylococcus aureus ATCC ${ }^{\circledR}$ 25923, Streptococcus mutans ATCC 35668 [53].

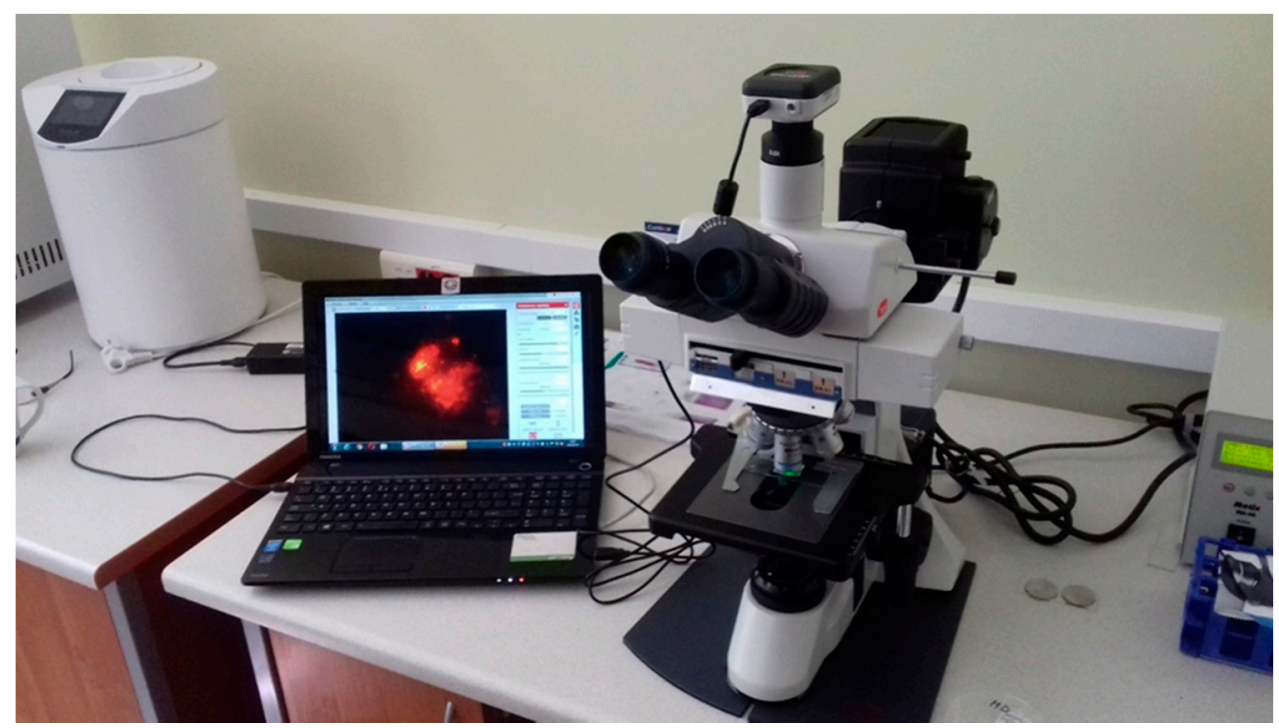

Figure 3. Fluorescence microscope equipped with a special MOTIC light kit and an M2 digital camera used for research.

The tests of bacterial adhesion to the film were carried out on different types of film (single-layer (monoplex) laminate for packing ice cream, two-layer (duplex) laminate for packing ketchup, three-layer (triplex) laminate for packing coffee, four-layer (quadroplex) laminate for packing mustard) and different films modified with six differ carbon-based nanomaterials (finally 24 new films were obtained via modification with carbon-based nanomaterials).

\section{Results and Discussion}

The research began to characterize the physico-chemical properties of selected carbon nanomaterials that were planned to be used for the modification of food packaging materials. One of the analysis methods of surface morphology carbon-based nanomaterials used was scanning electron microscopy (SEM). Thus, it was assumed that it is not essential to accurately determine the size of conglomerates and micro- and nano-structures, although it would be very helpful in optimizing the parameters of nanopowders and selecting them for further research. The smallest conglomerate size was observed for this nanomaterial.

SEM images of the tested carbon-based nanomaterials (CBNs) are presented in Figure 4. Figure 4 a shows the morphology of graphene flakes in the form of a film, Figure $4 \mathrm{~b}$-the amorphous form of low-pressure diamond powder, Figure 4c,e-the morphologies of detonation nanodiamond particles chemically modified by hydroxyl groups (e) and rhodamine (c). Interestingly, in the case of detonated nanodiamonds chemically modified by the Fenton method (presence of hydroxyl groups on the surface (Figure 4e) and rhodamine B attached to hydroxyl groups on the surface of the nanodiamond (Figure 4c), it was found that both of these nanomaterials have very similar nanocrystalline assemblies. It was also found that both of these materials exhibit fluorescent properties similar to the 
autofluorescence of diamond. While the observed fluorescence of the modified rhodamine $B$ material is rather obvious, in the case of nanodiamond particles with hydroxyl groups on the surface, this property could be considered an important feature that ought to be used for research with fluorescence techniques. A similar form but without visible autofluorescence was observed for the unmodified detonated nanodiamond particle (Figure 4f). This observation may indicate that the important to obtaining the fluorescent properties of detonated nanodiamond is the introduction of the reactive groups or bonds on the its surface.

(a)

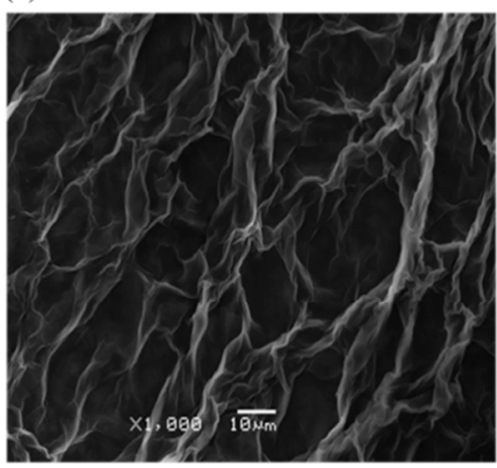

(d)

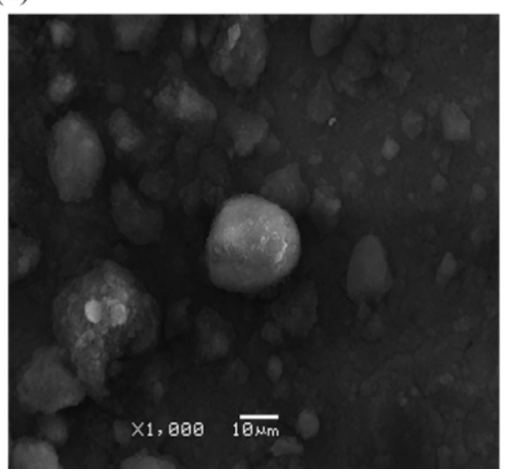

(b)

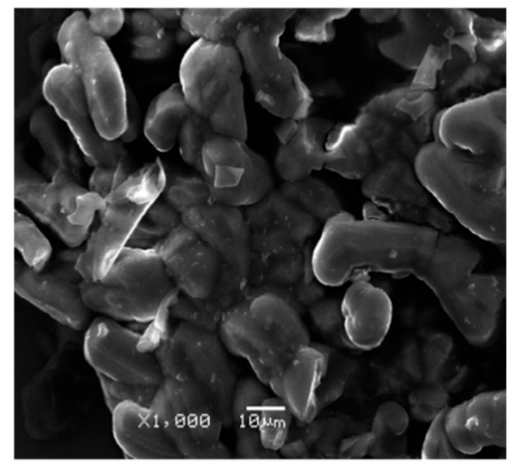

(e)

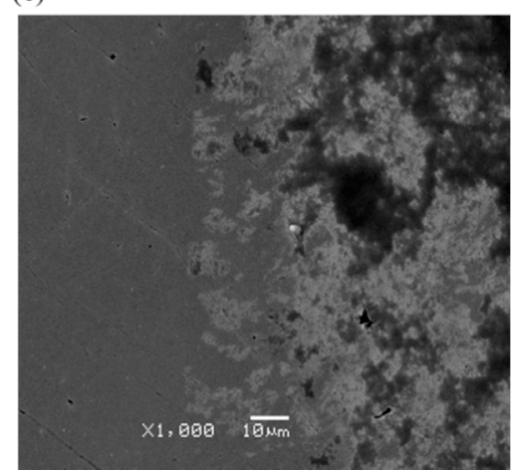

(c)

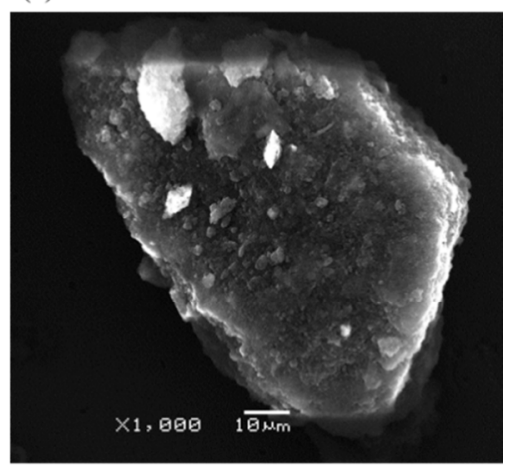

(f)

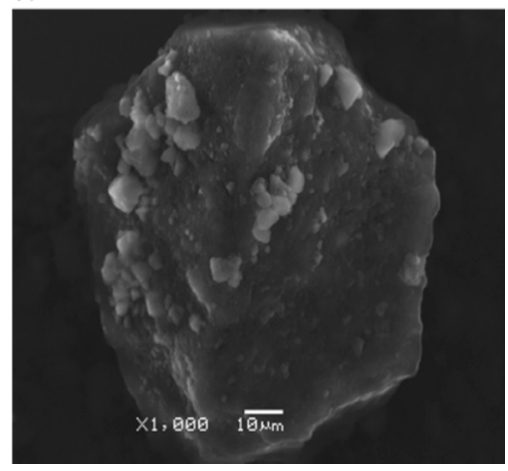

Figure 4. SEM images of the surface morphology Carbon-based Nanomaterials (CBNs): (a) graphene oxide (GO) film; (b) amorphous carbon powder formed using Radio Frequency Plasma Activated Chemical Vapor Deposition Method); (c) fluorescent nanodiamond (MDCHF), (d) plasma-chemically modified detonated nanodiamond particles (MDP1); (e) chemically modified detonated nanodiamond particles with hydroxyl functional groups (MDCHPOH); (f) pure detonated nanodiamond particles (DND).

The crystallographic structure of Carbon-based Nanomaterials (CBNs) is best described based on on XRD diffraction and High Resolution Transmission Electron Microscopy (HR TEM). The analysis of the atomic structure of detonation diamond crystals proved the nanoparticles form perfect single crystals. Some of the single crystals contain crystallographic defects [53,66-68].

Figure 5 shows the XRD analysis of examined detonation nanodiamond particles (DND) with the presence of the crystalline lattice parameters described in the abovecited publications. 


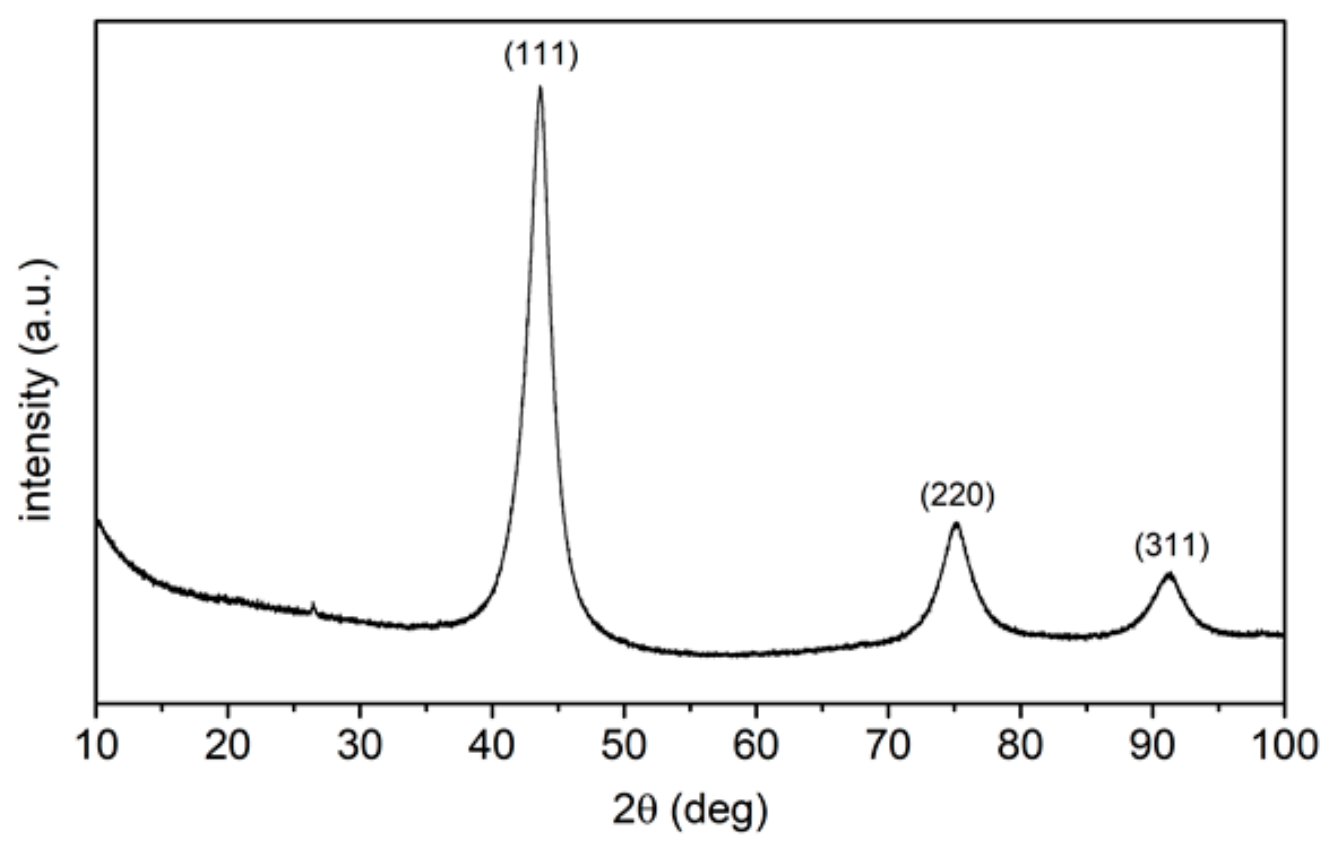

Figure 5. X-ray diffraction of a detonation nanodiamond particles (DND).

In order to study the surface morphology of examined carbon nanomaterials in more detail, confocal microscopy studies were performed (Figure 6).

The most ordered structure was observed for GO film, while the fluorescent nanodiamond powder (MDCHF) had the least ordered one. The remaining powders show similar surface characteristics.

The dynamic light scattering (DLS) method was used to evaluate the size of tested nanoparticles suspended in a liquid by using a laser beam. Using the DLS method the distribution of the single grain size nanoparticles depending on the method of manufacturing, surface modification and type of allotropic forms were obtained (Figure 7). The individual grain size of graphene oxide (GO) was $624.55 \mathrm{~nm}$ (Figure 7a). The observed large size of the grains may be due to the fact that GO emulsion was treated as a graphene film, which made the separation of individual grains difficult. Figure $7 \mathrm{~b}$ shows the results for amorphous carbon powder (RF) formed using the Radio Frequency Plasma Activated Chemical Vapor Deposition Method (RF/PACVD) method. For these particles, quite large grain sizes (about $153.44 \mathrm{~nm}$ ) were observed. The size of these grains results from the formation of conglomerates. Despite the efforts made, it was difficult to obtain single grains of RF material. For rhodamine modified detonated nanodiamond (MDCHF)—a fluorescent nanodiamond, the largest grain size $(163.10 \mathrm{~nm})$ was found (Figure $7 \mathrm{c})$. It appears that the measurement is being affected by the rhodamine B molecules covalently bound to diamond nanoparticles. The presence of a tertiary amine group and/or a positively charged iminium salt may cause grain repulsion because of the presence of positive charges on the nanomaterial surface. In the case of plasma-chemically modified detonated nanodiamond particles (MDP1) (Figure 7d) the grain size and individual grains were approximately $91.41 \mathrm{~nm}$ in size. The formation of a cluster of single, very small grains was found. Additionally, minor differences in the spherical shape of the molecules were observed. For chemically modified with hydroxyl groups (MDCHPOH) under Fenton reaction detonated nanodiamond particles the smallest grain sizes (about $4.20 \mathrm{~nm}$ ) were observed (Figure 7e). Modification of surface by the Fenton method purifies the surface of the nanodiamonds from undesirable deposits, which contributes to reducing the grain size. It seems, however, that the main reason for the observed small size of the grains is the presence of hydroxyl groups on the surface of the nanomaterial, which can form a network of hydrogen bonds between the grains and/or in the aqueous medium create grain structures surrounded by water molecules with the participation of hydrogen bonds. In the case of non-modified detonated 
nanodiamond particles (DND) very large conglomerates at 2.6 microns $(2658.73 \mathrm{~nm})$ were found (Figure 7f). The single grain size specification of the individual particles, provided by Adamas Nanotechnologies Company, is in the range from 2 to $4 \mathrm{~nm}$. So, these commercial detonation nanodiamond (DND) particles are able to form conglomerates from several hundred $\mathrm{nm}$ to a few $\mu \mathrm{m}$ in size with a highly developed reactive surface.

(a)

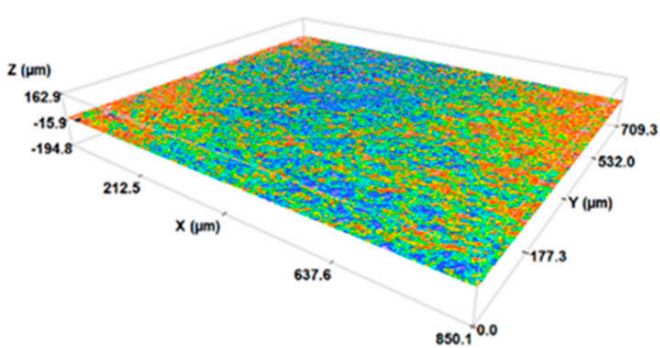

(c)

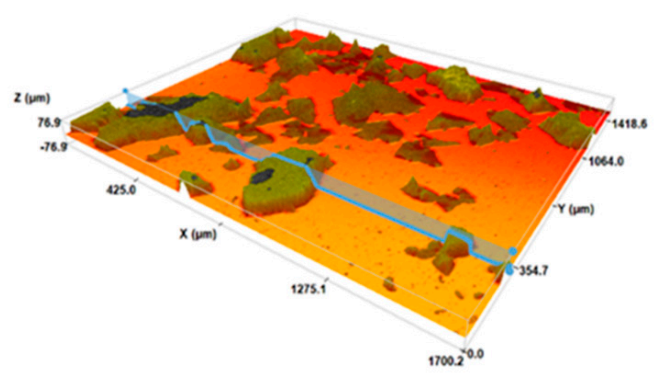

(e)

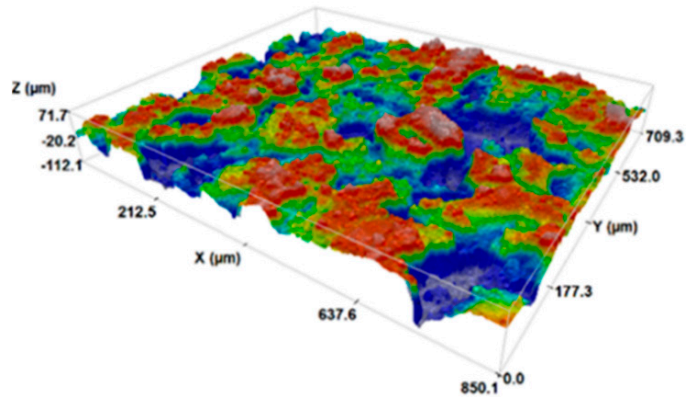

(b)
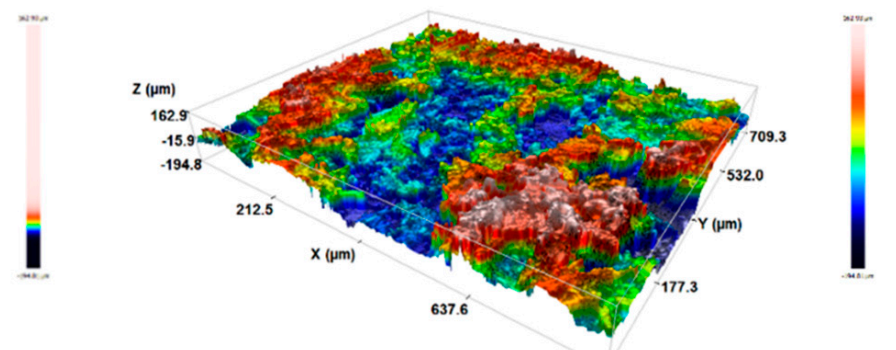

(d)
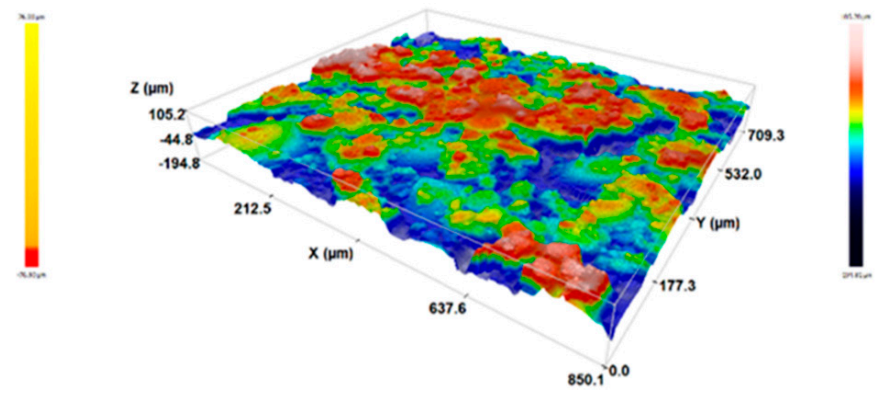

(f)
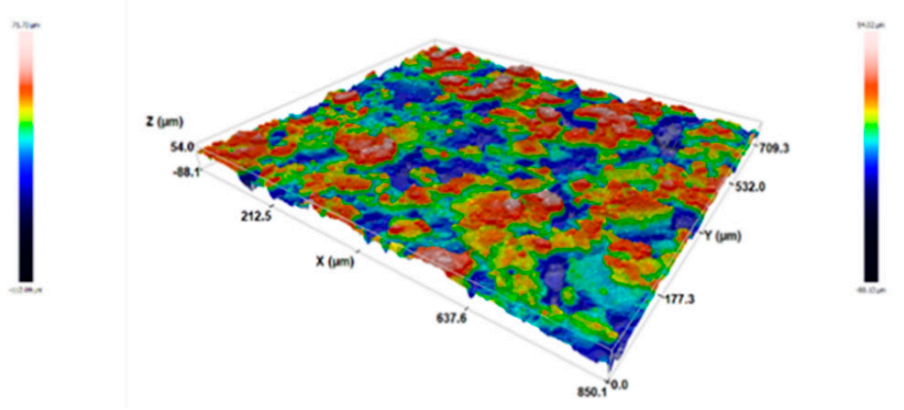

Figure 6. Confocal microscope images of Carbon-based Nanomaterials: (a) Graphene Oxide (GO) emulsion; (b) amorphous carbon powder formed using Radio Frequency Plasma Activated Chemical Vapor Deposition Method (RF); (c) fluorescent nanodiamond (MDCHF), (d) plasma-chemically modified detonated nanodiamond particles (MDP1); (e) chemically modified detonated nanodiamond particles with hydroxyl functional groups $(\mathrm{MDCHPOH}) ;(\mathbf{f})$ pure detonated nanodiamond particles (DND). 
(a)

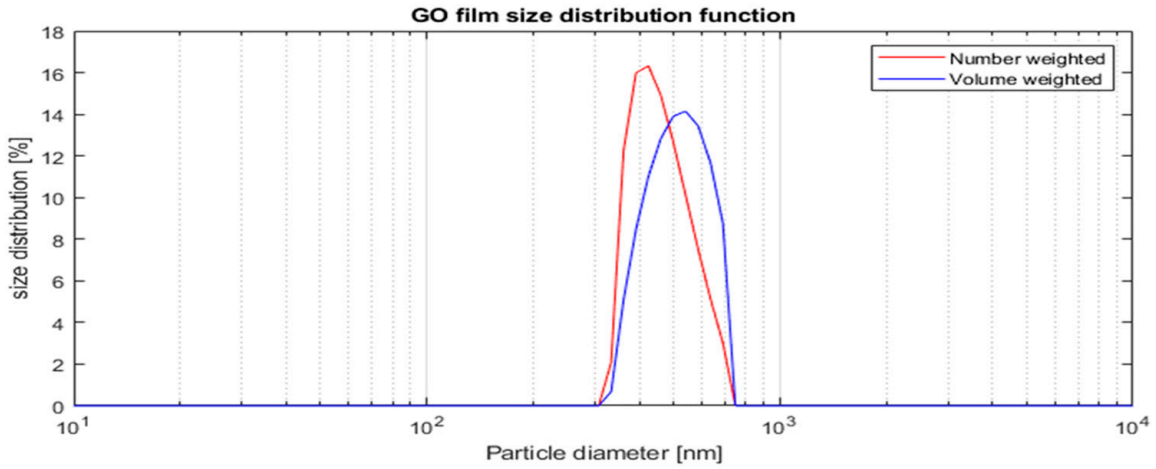

(b)

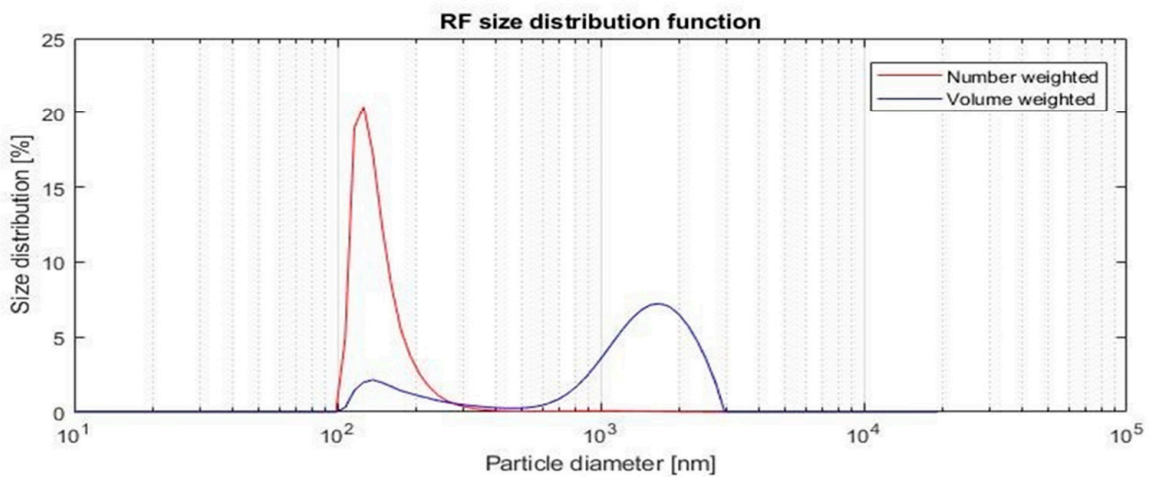

(c)

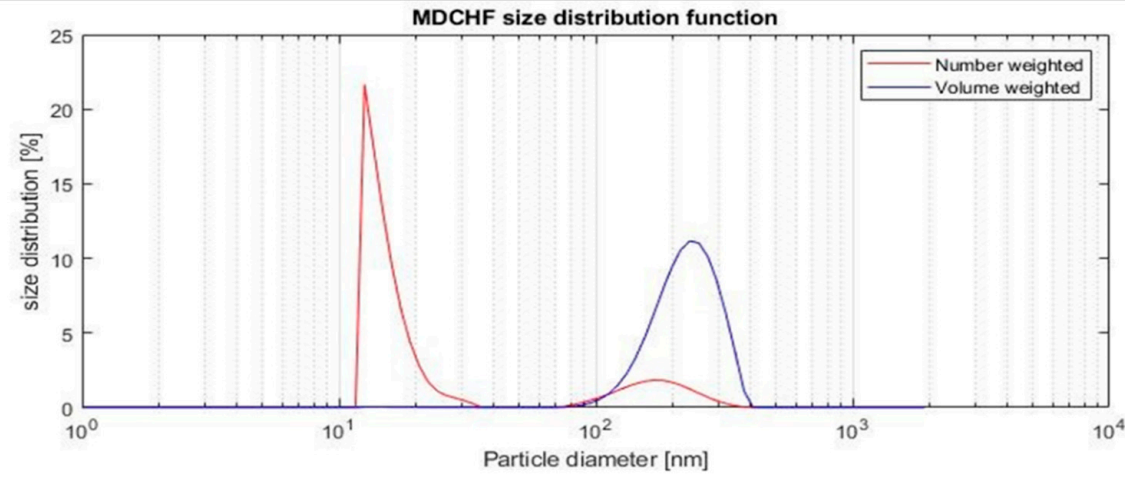

(d)

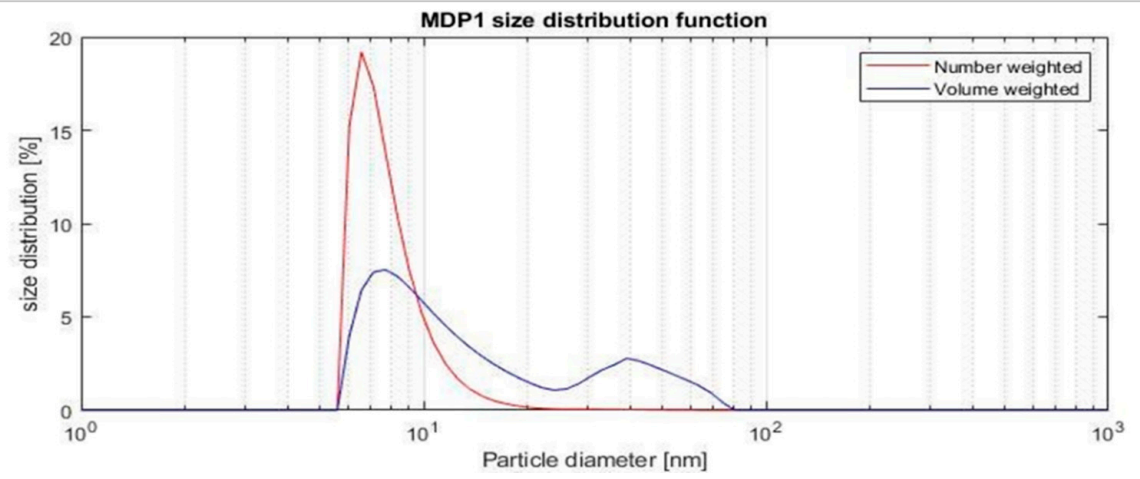

Figure 7. Cont. 
(e)

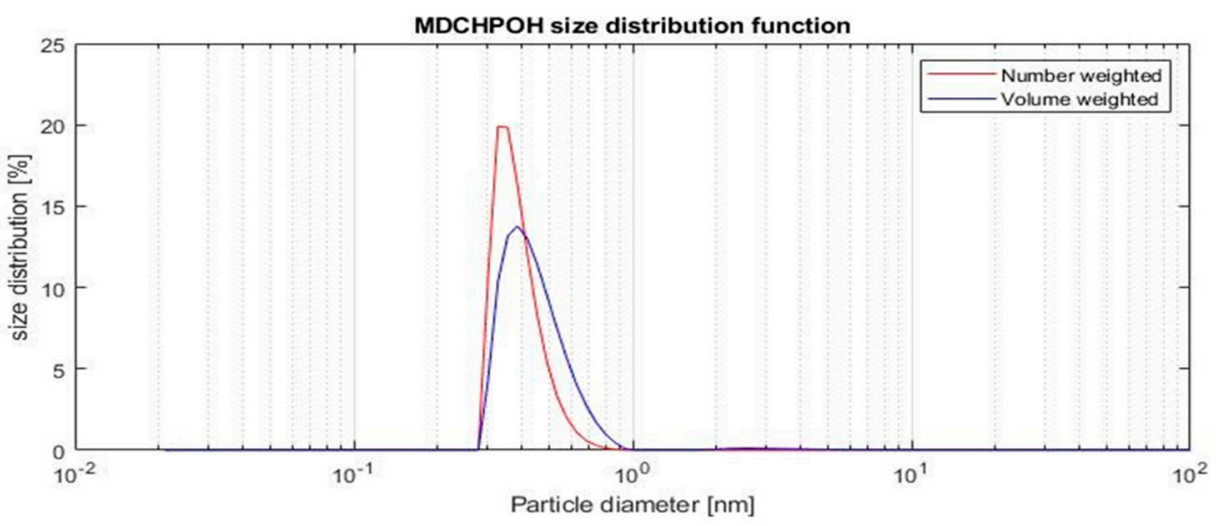

(f)

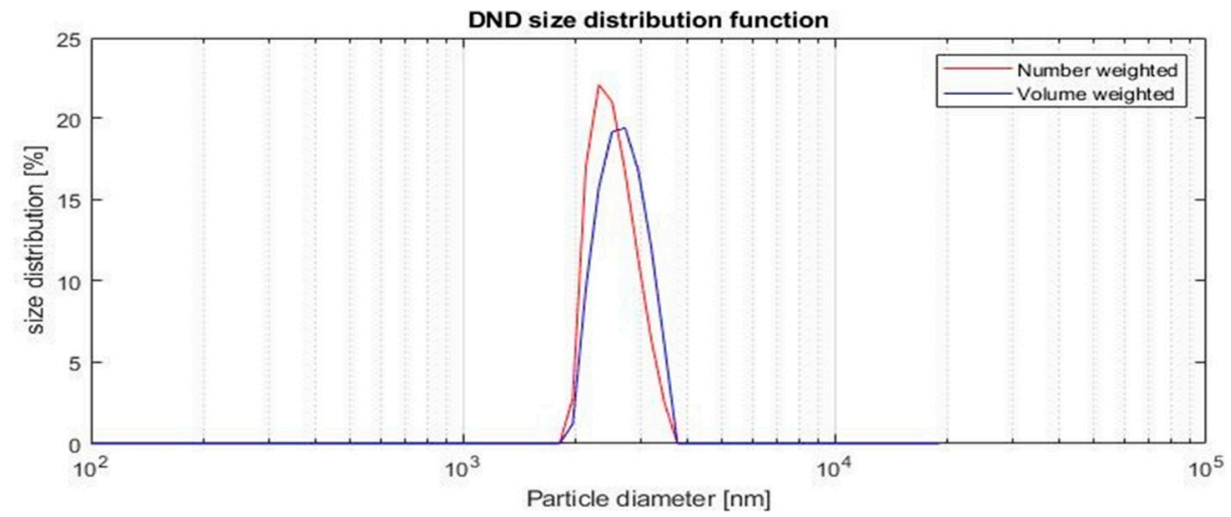

Figure 7. CBNs particle size based on DLS analysis (distribution function depending on number or volume weight): (a) Graphene Oxide (GO) film; (b) amorphous carbon powder formed using Radio Frequency Plasma Activated Chemical Vapor Deposition Method (RF); (c) fluorescent nanodiamond (MDCHF), (d) plasma-chemically modified detonated nanodiamond particles (MDP1); (e) chemically modified detonated nanodiamond particles with hydroxyl functional groups (MDCHPOH); (f) pure detonated nanodiamond particles (DND).

The smallest grain size was found for particles of detonated nanodiamond chemically modified with hydroxyl groups on the surface $(\mathrm{MDCHPOH})$ and the plasmachemically modified detonation nanodiamond particles (MDP1) (Figures 7d and 8), while the largest single grain size had unmodified detonation nanodiamond particles (DND) (Figures $7 \mathrm{f}$ and 8 ). This finding was surprising because it was claimed that this commercial powder had a single grain size in the range $2 \mathrm{~nm}$ to $4 \mathrm{~nm}$. The observed differences may result from disregarding the spontaneous ability of DND to form conglomerates. It seems that the application of the DLS method gave the opportunity to find the real size of agglomerates of 3D nanodiamond particles. Chemical modification, i.e., surface hydroxylation and saturation of free bonds on the diamond surface significantly affects the breakdown of conglomerates and the possibility of obtaining a single grain size in the $4 \mathrm{~nm}$ range. Confirmation of this hypothesis was also obtaining a single grain below $100 \mathrm{~nm}$ for the plasma-chemical modified material (MDP1). The functionalization of the nanodiamond surface, saturation of free reactive bonds and the exposure of active carbonyl groups [3] during plasma-chemical modification means that when considering a single nanodiamond grain, it is necessary to modify its surface and disturb the formation of conglomerates. The attachment of fluorescent labels by a strong covalent bond with rodamine B (MDCHF) causes the modified material to have a tendency to form conglomerates, hence the size of a single grain above $100 \mathrm{~nm}$ [3] (Figure 8). A notable point of interest was the result of amorphous carbon powder formed using the Radio Frequency Plasma Activated Chemi- 
cal Vapor Deposition Method (RF). It is known from the literature [69] that this powder contains much less diamond phase than detonated nanodiamond particles, leading to an amorphous structure containing a significant amount of graphite phase, which determines its hydrophobicity and related morphology.

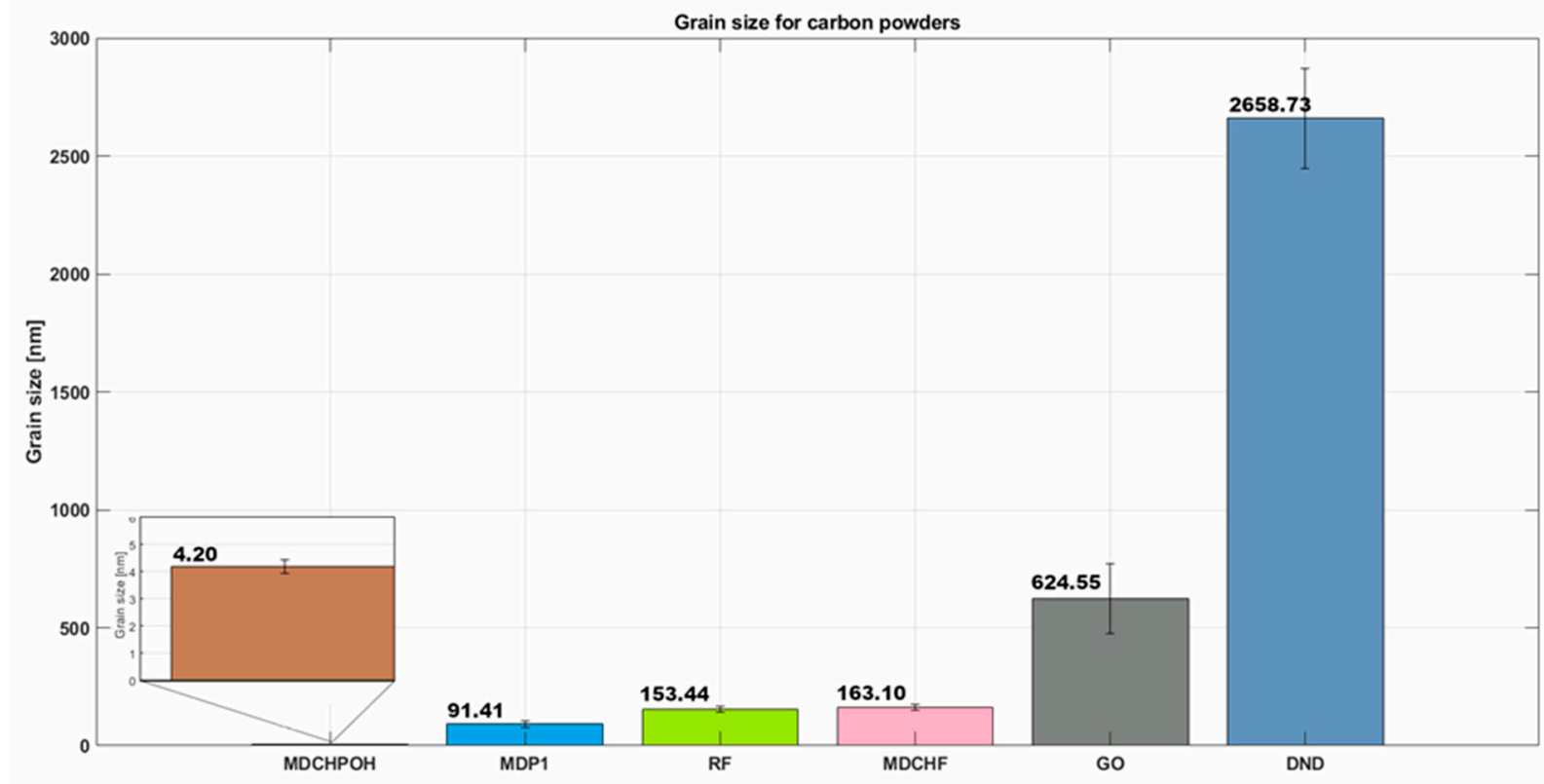

Figure 8. The comparison of grain sizes of tested carbon-based nanomaterials.

The size of the graphene oxide (GO) flakes was the most difficult to interpret, since the flakes were a suspension in water and formed a film. The size of a single grain was estimated to be slightly above 0.5 microns.

For designation zeta potential using DLS method, the parameters to be monitored were set prior to the start of a series of tests: measurement cell, omega cuvette $Z$, approximation, adjustment mode, automatic, Debye factor: 1.5, equilibration time: $0 \mathrm{~h} 01 \mathrm{~m} 00 \mathrm{~s}$, target temperature: $20.0^{\circ} \mathrm{C}$ or $25.0^{\circ} \mathrm{C}$, voltage: $200.0 \mathrm{~V}$, run mode automatic, number of runs: $100 \div 1000$; solvent name: water, solvent viscosity: 0.0010019 Pas, solvent refractive index: 1.3307, solvent Relative permittivity: $80.18 \mathrm{r}$. The zeta potential results of all the carbon-based nanomaterials tested are shown in Figure $9 \mathrm{a}-\mathrm{f}$. The Zeta potential of graphene oxide (GO) emulsion in water was $-22.97 \mathrm{mV}$. For the amorphous carbon powder formed using Radio Frequency Plasma Activated Chemical Vapor Deposition Method (RF) suspended in water, a mean zeta potential of $-34.97 \mathrm{mV}$ was found. In the case of fluorescent nanodiamond (MDCHF), the zeta potential of powder suspended in water there was a mean zeta potential of $-16.83 \mathrm{mV}$. In Figure 9d, the zeta potential of plasma-chemically modified detonated nanodiamond particles (MDP1) is shown. For the suspension of powder in water gained mean zeta potential on $-0.1 \mathrm{mV}$ tier was found. The zeta potential of chemically modified detonated nanodiamond particles with hydroxyl functional groups (MDCHPOH) gained a mean zeta potential of $46.30 \mathrm{mV}$. The zeta potential diamond powders produced by detonation method (DND) as a water suspension gained a mean zeta potential of $-6.47 \mathrm{mV}$.

Examination of the electrokinetic potential allowed the determination of the sign and value of the electric potential on the border of the adsorptive and diffusion phase (Figure 10). It is an indicator of the type of environment prevailing around the tested carbon powders. Positive potentials, maximum value $46.3 \mathrm{mV}$, for diamond powders modified by hydroxyl groups (MDCHPOH), due to attractive electrostatic force may form friendly environment to create stronger ion binds and increase adhesion Gram-negative bacteria to powders surfaces, similarly negative potentials, minimum value of $-34.95 \mathrm{mV}$ 
for amorphous carbon powders obtained by Radio Frequency Plasma Activated Chemical Vapor Deposition Method may create friendly environment to create stronger ion binds and increase adhesion for Gram positive bacteria to powders surfaces [70-72].

(a)

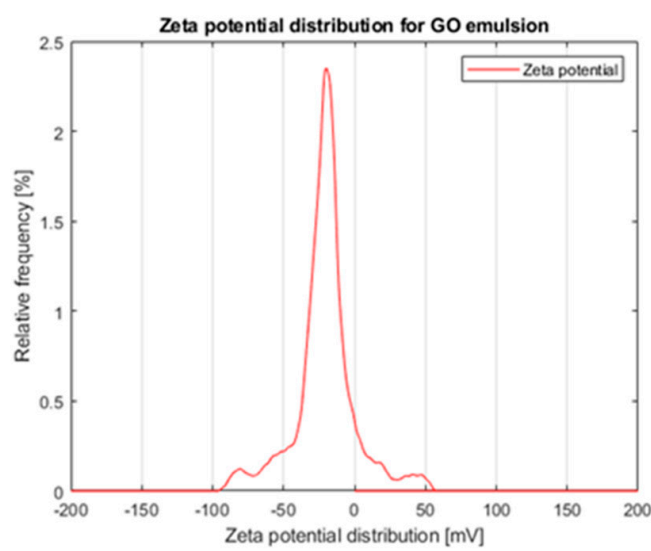

(c)

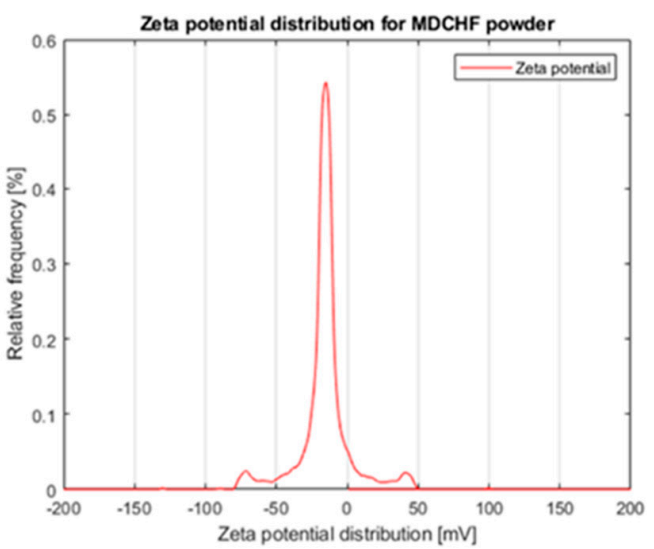

(e)

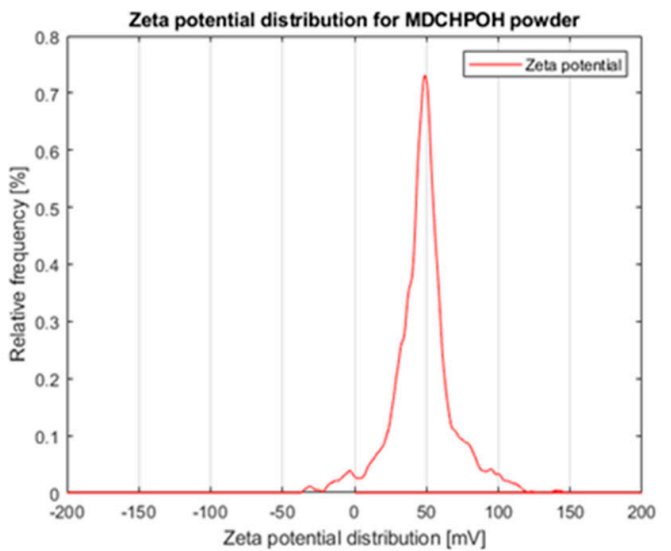

(b)

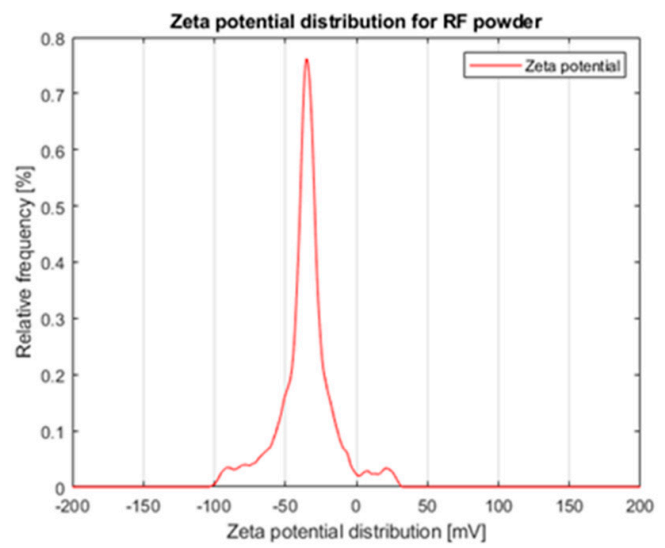

(d)

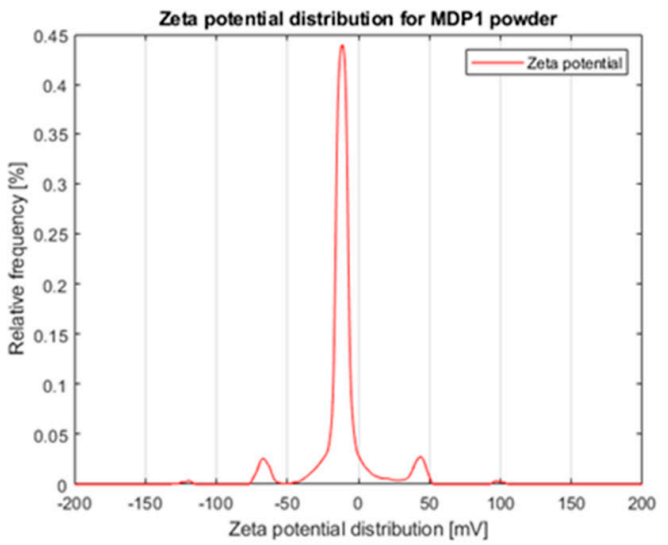

(f)

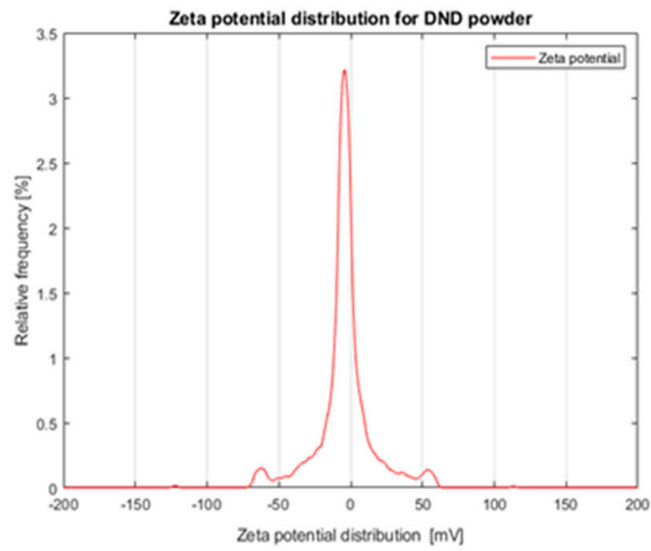

Figure 9. Zeta potential of Carbon-based Nanomaterials: (a) Graphene Oxide (GO) emulsion; (b) amorphous carbon powder formed using Radio Frequency Plasma Activated Chemical Vapor Deposition Method (RF); (c) fluorescent nanodiamond (MDCHF), (d) plasma-chemically modified detonated nanodiamond particles (MDP1); (e) chemically modified detonated nanodiamond particles with hydroxyl functional groups (MDCHPOH); (f) pure detonated nanodiamond particles (DND). 


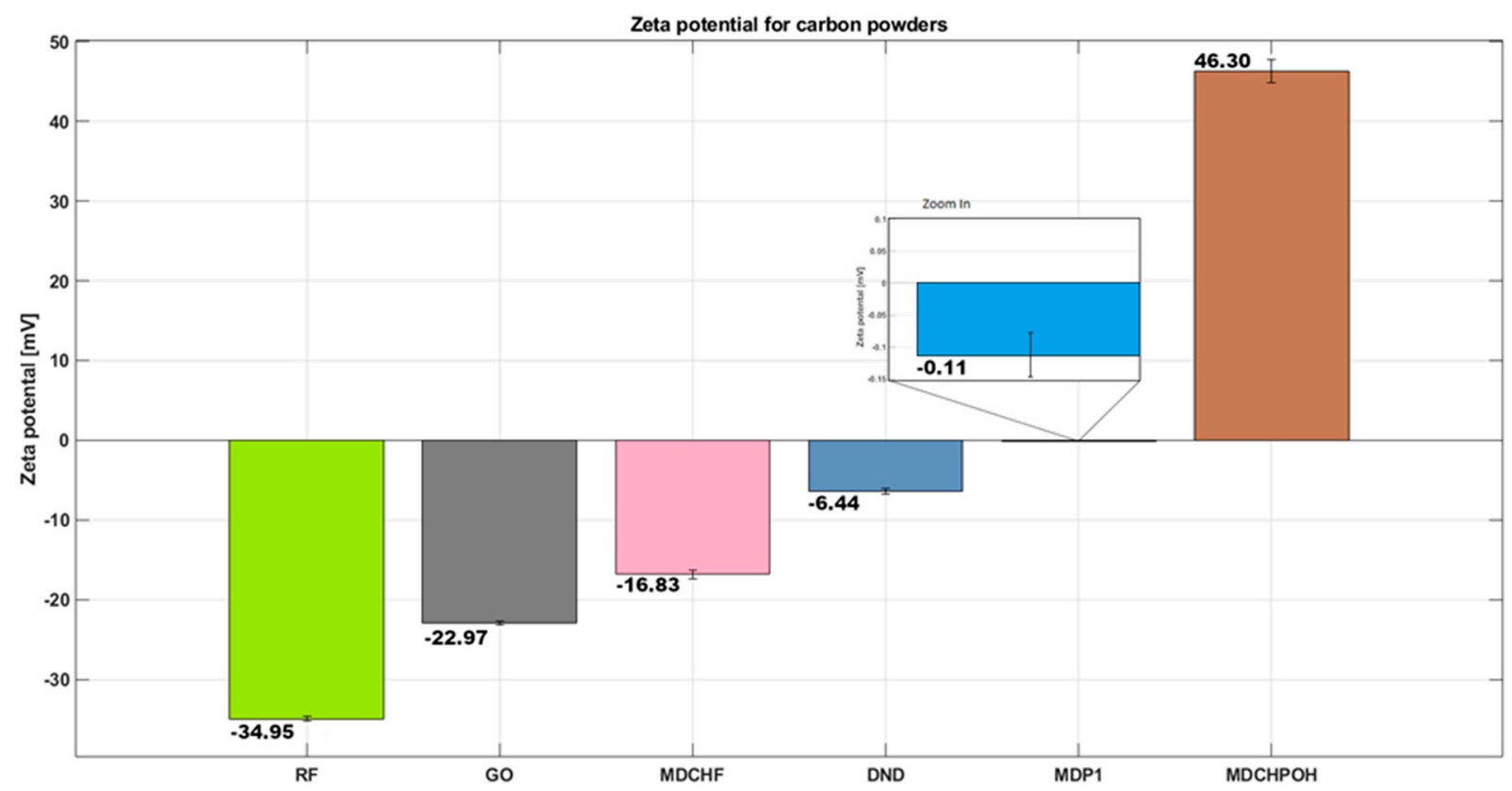

Figure 10. A comparison of tested carbon powders in relation to zeta potential.

Also noteworthy is electrokinetic potential near " 0 " value, $-0.11 \mathrm{mV}$ for plasmachemical modified diamond powder (MDP1), which may induce a practically neutral environment.

In order to additionally check the content of the diamond phase in the tested carbonbased nanomaterials, their structure was checked by Raman spectroscopy. Figure 11 shows the results of the examined carbon nanostructures under Raman spectroscopy. The greatest content of the diamond phase is shown by the following powders: fluorescent detonation nanodiamond modified by rhodamine (MDCHF) ID/IG-2.39 and plasma-chemically modified (MDP1) ID/IG-2.24.

The following powders have an intermediate content of the diamond phase: pure detonation method (DND)-ID/IG-0.93 and detonation nanodiamond particles modified by chemical method with hydroxyl groups (MDCHPOH)-ID/IG-0.63. The amorphous powder shows the lowest content of diamond phase carbon powder manufactured by the RF PACVD method (RF)-ID/IG-0.55. The graphene oxide film has a high ID/IG ratio, which is not due to the high content of the diamond phase, but to lattice defects.

In the next stage of the research, the antibacterial activity of all the tested carbonbased nanomaterials was checked. Inhibition zone assay was used in the studies. For microbiological tests 4 bacterial strains were used: Escherichia coli, Streptococcus mutans, Pseudomonas aeruginosa, and Staphylococcus aureus. The inhibition zones were formed by the modified disk diffusion method. The zones of bacterial growth inhibition were visible in the case of direct contact: pure detonated nanodiamond particles (DND) with Escherichia coli (Figure 12a), a DND with Streptococcus mutans (Figure 12b), chemically modified detonated nanodiamond particles with hydroxyl functional groups (MDCHPOH) with Pseudomonas aeruginosa (Figure 12c), amorphous carbon powder formed using Radio Frequency Plasma Activated Chemical Vapor Deposition Method (RF) with Staphylococcus aureus (Figure 12d), a fluorescent nanodiamond (MDCHF) with Escherichia coli (Figure 12e), Graphene Oxide (GO) film with Pseudomonas aeruginosa (Figure 12f) and Graphene Oxide (GO) film with Streptococcus mutans (Figure 12g). 

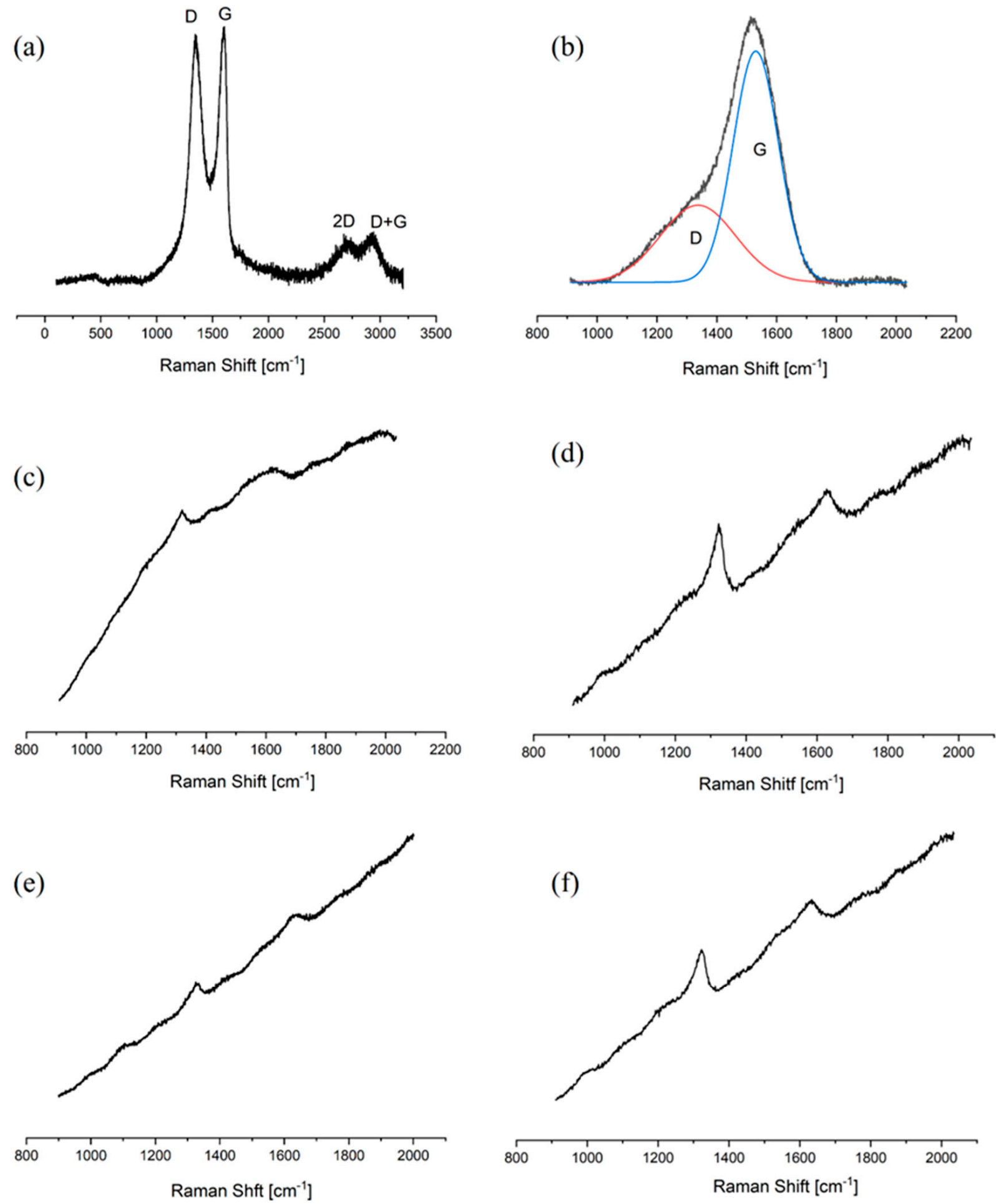

Figure 11. Raman spectroscopy images of Carbon-based Nanomaterials: (a) Raman spectrum of graphene oxide film (GO)-ID/IG-2.25; (b) Raman spectrum of amorphous carbon powder manufactured by RF PACVD method (RF)-ID/IG-0.55; (c) Raman spectrum of fluorescent detonation nanodiamond modified by rhodamine (MDCHF)-ID/IG-2.39; (d) Raman spectrum of detonation nanodiamond particles modified by plasma-chemical method (MDP1)-ID/IG-2.24; (e) Raman spectrum of detonation nanodiamond particles modified by chemical method with hydroxyl groups (MDCHPOH)-ID/IG0.63; (f) Raman spectrum of detonation nanodiamond particles manufactured by detonation method (DND)-ID/IG-0.93. 

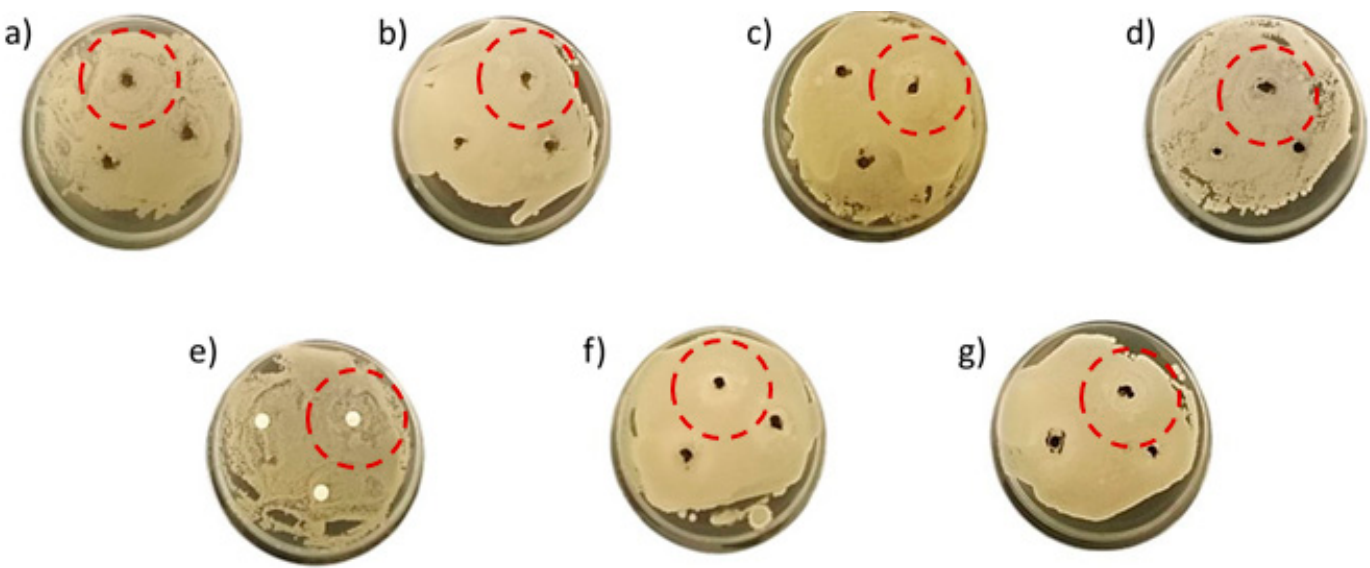

Figure 12. Results of antibacterial studies based on the inhibition zone method for: (a) pure detonated nanodiamond particles (DND) with Escherichia coli; (b) DND with Streptococcus mutans; (c) chemically modified detonated nanodiamond particles with hydroxyl functional groups (MDCHPOH) with Pseudomonas aeruginosa; (d) amorphous carbon powder formed using Radio Frequency Plasma Activated Chemical Vapor Deposition Method (RF) with Staphylococcus aureus; (e) fluorescent nanodiamond (MDCHF) with Escherichia coli; (f) Graphene Oxide (GO) film with Pseudomonas aeruginosa; (g) GO film with Streptococcus mutans.

The results of microbiological tests do not clearly indicate the relationship between the surface of detonated nanodiamond particles and their bactericidal activity. The large conglomerates of unmodified detonating nanodiamond particles (DND), most likely in the cytotoxic mechanism, had a non-significant bactericidal effect (Figure 11a,b). Other powders, except for the plasma-chemically modified powder (MDPOH) without bactericidal properties, had selective and weak bactericidal activity (Figure 11c-e). This is consistent with the literature and our own research, in which nanodiamonds did not show any significant bactericidal activity $[2-4,6,11,18-21]$.

Graphene oxide had antibacterial activity in relation to Pseudomonas aeruginosa and Streptococcus mutans, which determines the visible inhibition zone (Figure 12f,g). Also, here the obtained result is consistent with the literature data [12-14,42].

In the last stage of the research, the influence of packaging materials modified with all tested carbon-based nanomaterials on food was examined. Then the bacterial strains (Escherichia coli ATCC 25922, Pseudomonas aeruginosa NCTC 12903/ATCC 27853, Streptococcus mutans ATCC 35668, Staphylococcus aureus ATCC25923) were applied. Staphylococcus aureus, Streptocococcus mutant as Gram-positive bacteria should multiply intensively in an environment formed by materials with negative electrokinetic potentials (almost all except $\mathrm{MDCHPOH}$ ). $\mathrm{MDCHPOH}$ with a high positive potential should allow Gram-negative bacteria (Pseudomonas aeruginosa, Escherichia coli) to propagate intensively. Plasma-chemical modified diamond powder (MDP1) should not have a big influence on antibacterial behavior. The results of adhesion of bacteria for food films coated with powders of carbon-based nanomaterials are presented in Table 1 . No data applies to results that are statistically non-existent and do not affect the final results of the study.

To analyze the images from the fluorescence microscope, bacteria were colored: yellow-live, red-dead. In the research various carbon-based nanomaterial types of films for food were utilised (I—-mustard, II-ice cream, III—ketchup, IV—coffee). For Staphylococcus aureus, Streptococcus mutans, Pseudomonas aeruginosa, Escherichia coli both increase and decrease of bacterial adhesion to food laminates were observed (Figures 13-16). Research on the adhesion of Staphylococcus aureus to packaging film for food modified with carbon-based nanomaterials allowed for the selection of materials with a high degree of adhesion, as well as those for which adhesion was low. In the case of packaging films modified with graphene oxide (GO), an increase in bacterial adhesion was observed on modified food mustard films (I) and a decrease in bacterial adhesion on modified food 
ketchup films (III) (Figure 13a). Application of an amorphous carbon powder formed using Radio Frequency Plasma Activated Chemical Vapor Deposition Method (RF) for the modification of the food film enabled the observation that an increase in bacterial adhesion was found on modified films for ice cream packaging (II) and a decrease in bacterial adhesion on all modified food ketchup films (III) (Figure 13b). Fluorescent detonation nanodiamond modified by rhodamine (MDCHF) coated laminates were causing an increase in bacterial adhesion on modified food ice cream films (II) and a decrease in bacterial adhesion on modified food ketchup films (III) (Figure 13c).

Table 1. The adhesion of bacteria for food films coated with carbon powders.

\begin{tabular}{|c|c|c|c|c|c|c|c|}
\hline Bacteria & Food Packaging & GO & $\mathbf{R F}$ & MDCHF & MDP1 & МDCHРОН & DND \\
\hline \multirow{4}{*}{$\begin{array}{c}\tilde{\Xi} \\
\stackrel{\Xi}{\Xi} \\
\stackrel{\Xi}{\Xi} \\
\dot{\Xi}\end{array}$} & mustard & nd & nd & - & nd & + & nd \\
\hline & ice crem & nd & nd & nd & -- & ++ & nd \\
\hline & ketchup & nd & nd & - & + & nd & nd \\
\hline & coffee & - & nd & nd & nd & + & nd \\
\hline \multirow{4}{*}{$\begin{array}{l}\stackrel{D}{\Xi} \\
\stackrel{\Xi}{\Xi} \\
\stackrel{\Xi}{\Xi} \\
\dot{\omega}\end{array}$} & mustard & nd & nd & nd & nd & + & nd \\
\hline & ice crem & - & nd & nd & + & nd & nd \\
\hline & ketchup & - & nd & + & nd & nd & nd \\
\hline & coffee & -- & nd & ++ & nd & nd & nd \\
\hline \multirow{4}{*}{ 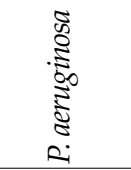 } & mustard & ++ & nd & nd & - & nd & nd \\
\hline & ice crem & nd & - & nd & nd & nd & nd \\
\hline & ketchup & - & nd & nd & nd & + & nd \\
\hline & coffee & -- & nd & nd & + & nd & nd \\
\hline \multirow{4}{*}{$\begin{array}{l}\ddot{8} \\
\dot{8} \\
\dot{0}\end{array}$} & mustard & nd & + & nd & -- & nd & nd \\
\hline & ice crem & nd & - & nd & nd & ++ & nd \\
\hline & ketchup & nd & + & nd & nd & nd & nd \\
\hline & coffee & nd & - & nd & nd & + & nd \\
\hline
\end{tabular}

+ means that the greatest increase in adhesion was observed; ++ means the maximum increase in adhesion compared to all powders and all types of food films; - means that a significant decrease in adhesion was noted; - - maximum decrease in adhesion compared to all powders and all types of food films; nd means no data.

Plasma-chemically modified detonated nanodiamond particles (MDP1) coated laminates resulted in an increase in bacterial adhesion on ketchup films (III) and a decrease in bacterial adhesion on ice cream films (II) (Figure 13d). In the case of chemically modified detonated nanodiamond particles with hydroxyl functional groups (MDCHPOH) coated laminates, an increase in bacterial adhesion was observed on ice cream films (II) and a decrease in bacterial adhesion on ketchup films (III) (Figure 13e). Nanodiamond particles manufactured by the detonation method (DND) coated laminates resulted to an increase in bacterial adhesion on coffee films (IV) and a decrease in bacterial adhesion on mustard films (I) (Figure 13e). In the case of the remaining bacteria, identical tests of bacterial adhesion to food films modified with nanomaterials were performed. Figure 14 shows the results of Streptococcus mutans adhesion to laminates for food films: I-mustard, II-ice cream, III—-ketchup, IV—coffee.

Also, in the case of research on the adhesion of Streptococcus mutans to packaging film for food modified with carbon-based nanomaterials allowed for the selection of materials with a high degree of adhesion, as well as those for which adhesion was low. An increase of bacterial adhesion to graphene oxide (GO) coated laminates for ketchup films (III) and a decrease in bacterial adhesion on graphene oxide (GO) modified food coffee films (IV) was found (Figure 14a).

Application of an amorphous carbon powder formed using Radio Frequency Plasma Activated Chemical Vapor Deposition Method (RF) for the modification of the food film allowed the observation that an increase in bacterial adhesion was found on modified food ketchup films (III) and a decrease in bacterial adhesion on all modified food coffee films (IV) (Figure 14b). When fluorescent detonation nanodiamond modified by rhodamine 
(MDCHF) and plasma-chemically modified detonated nanodiamond particles (MDP1) were used for the modification of food films, similar results were observed (Figure 14c,d). In both cases, an increase in bacterial adhesion was observed on modified food coffee films (IV) and a decrease in bacterial adhesion on all modified food mustard films (I).

The application of nanodiamond modified chemically with hydroxyl functional groups (MDCHPOH) for film the laminates led to an increase in bacterial adhesion on modified food ketchup films (III) and a decrease in bacterial adhesion on modified food ice cream films (II) (Figure 14e). In the case of nanodiamond particles manufactured by detonation method (DND) coated laminates, an increase in bacterial adhesion was observed on modified food coffee films (IV) and a decrease in bacterial adhesion on modified food mustard films (I) (Figure 14f).

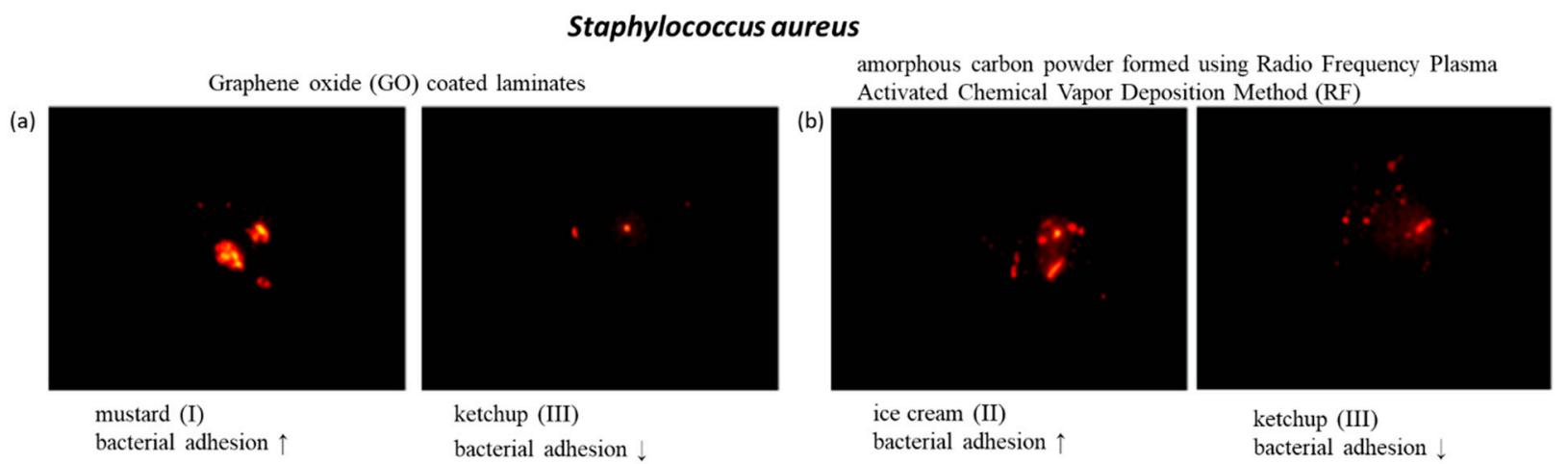

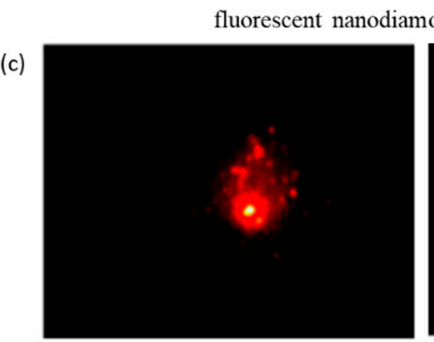

ice cream (II) bacterial adhesion $\uparrow$ bacterial adhesion $\downarrow$ ketchup (III)

bacterial adhesion

plasma-chemically modified detonated nanodiamond particles (MDP1)

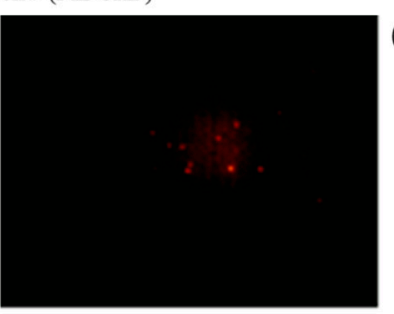

ketchup (III)

bacterial adhesion

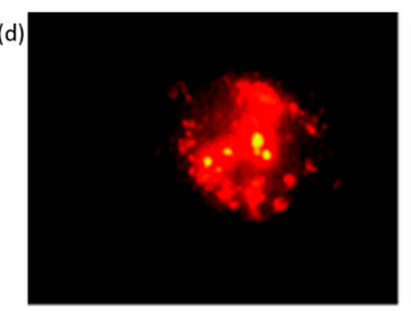

ketchup (III) bacterial adhesion $\uparrow$

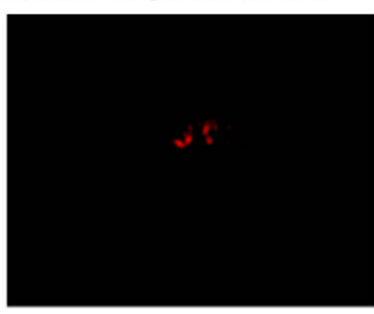

ice cream (II) bacterial adhesion $\downarrow$

chemically modified detonated nanodiamond particles with hydroxyl functional groups (MDCHPOH)

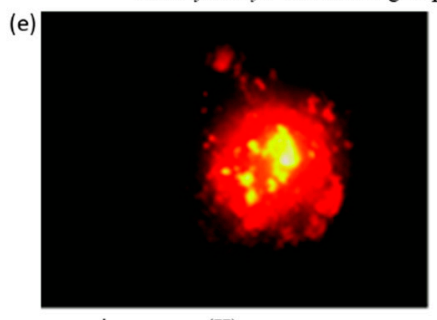

ice cream (II)

bacterial adhesion $\uparrow$

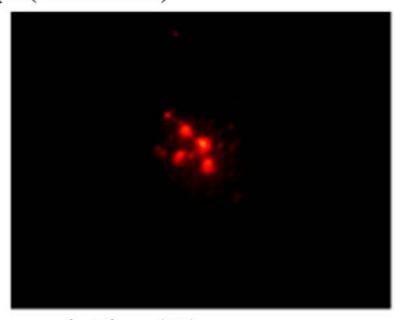

ketchup (III)

bacterial adhesion

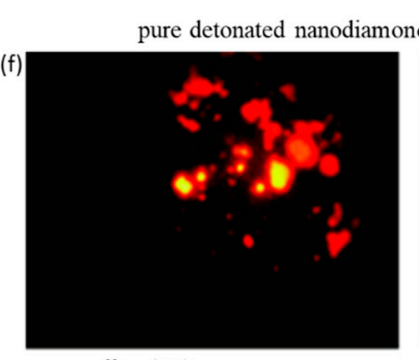

coffee (IV)

bacterial adhesion $\uparrow$

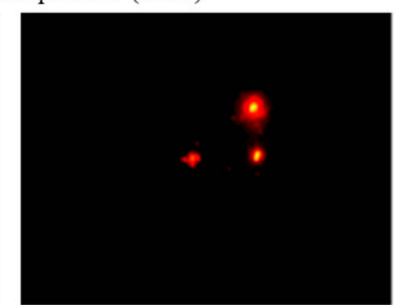

mustard (I)

bacterial adhesion

Figure 13. Images of Staphylococcus aureus adhesion to laminates for food films I-mustard, II-ice cream, III-ketchup, IV—coffee, with the lowest and highest adhesion to layers formed by: (a) Graphene Oxide (GO) film; (b) amorphous carbon powder formed using Radio Frequency Plasma Activated Chemical Vapor Deposition Method (RF); (c) fluorescent nanodiamond (MDCHF); (d) plasma-chemically modified detonated nanodiamond particles (MDP1); (e) chemically modified detonated nanodiamond particles with hydroxyl functional groups $(\mathrm{MDCHPOH})$; $(\mathbf{f})$ pure detonated nanodiamond particles (DND). 


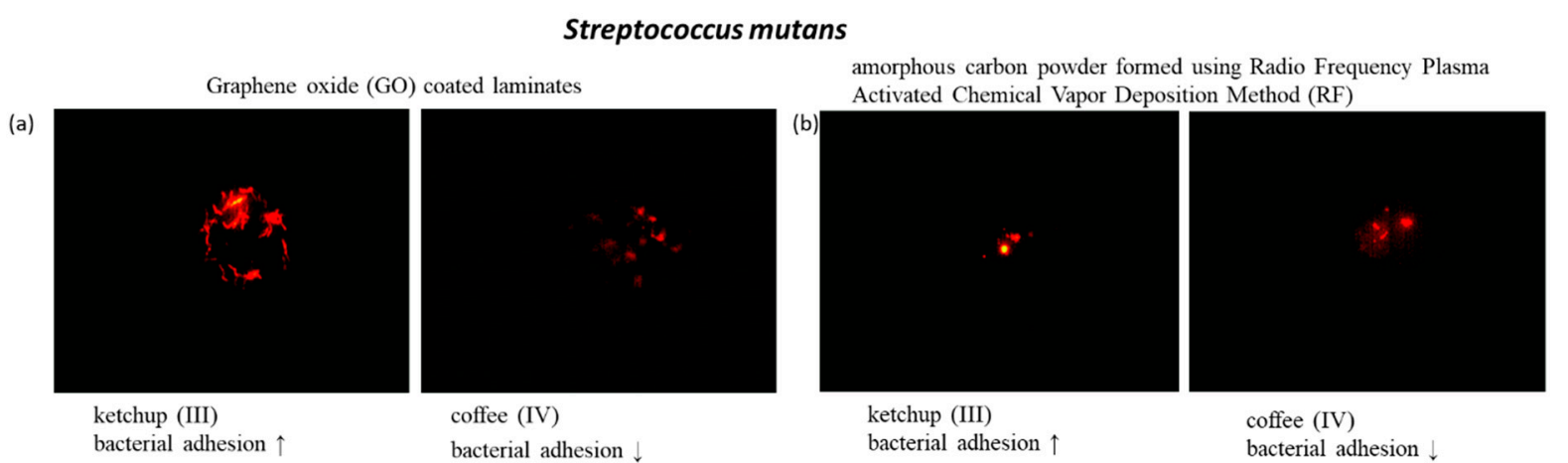

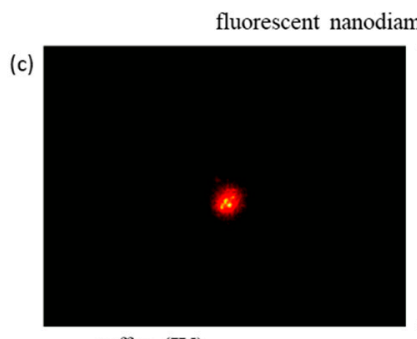

coffee (IV) bacterial adhesion $\uparrow$ bacterial adhesion

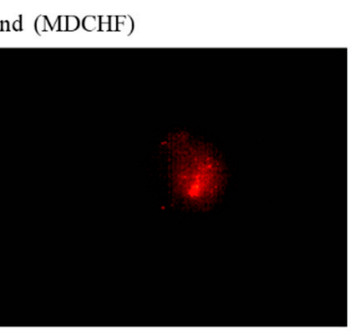

mustard (I)

bacterial adhesion

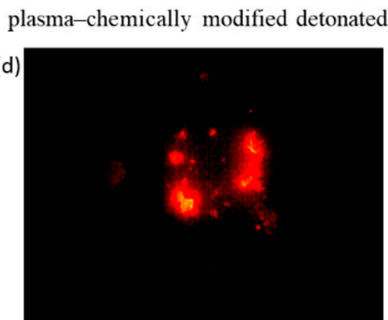

coffee (IV)

bacterial adhesion $\uparrow$ bacterial adhesion

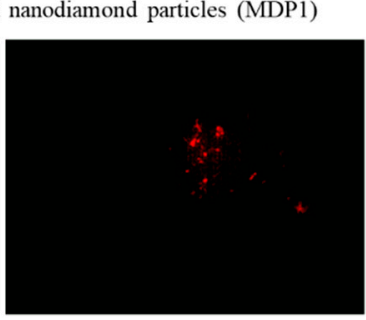

mustard (I)

bacterial adhesion $\downarrow$

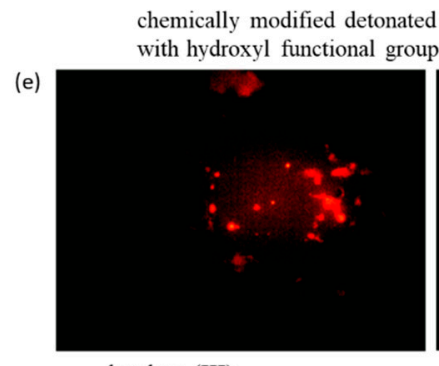

ketchup (III) bacterial adhesion $\uparrow$

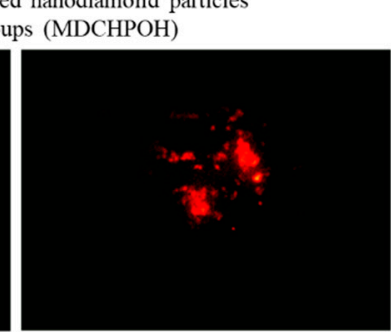

ice cream (II) bacterial adhesion

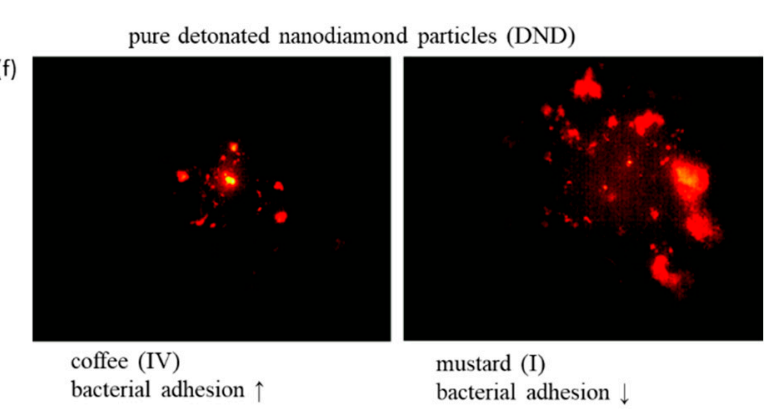

Figure 14. Images of Streptococcus mutans adhesion to laminates for food films I—mustard, II—ice cream, III—ketchup, IV_coffee, with the lowest and highest adhesion to layers formed by: (a) Graphene Oxide (GO) film; (b) amorphous carbon powder formed using Radio Frequency Plasma Activated Chemical Vapor Deposition Method (RF); (c) fluorescent nanodiamond (MDCHF); (d) plasma-chemically modified detonated nanodiamond particles (MDP1); (e) chemically modified detonated nanodiamond particles with hydroxyl functional groups $(\mathrm{MDCHPOH})$; (f) pure detonated nanodiamond particles (DND).

The characteristics of the adhesion capacity of Pseudomonas aeruginosa to food packaging films (Figure 15) modified with carbon nanomaterials is as follows: (a) graphene oxide (GO) coated laminates: an increase in bacterial adhesion was observed on modified mustard films (I) and a decrease in bacterial adhesion on modified coffee films (IV); (b) an amorphous carbon powder formed using Radio Frequency Plasma Activated Chemical Vapor Deposition Method (RF) coated laminates: an increase in bacterial adhesion was observed on modified coffee films (IV) and a decrease in bacterial adhesion on modified mustard films (I); (c) fluorescent detonation nanodiamond modified by rhodamine (MDCHF) coated laminates: an increase in bacterial adhesion was observed on modified mustard films (I) and a decrease in bacterial adhesion on modified ketchup films (III); (d) plasma-chemically modified detonated nanodiamond particles (MDP1) coated laminates: an increase in bacterial adhesion was observed on modified coffee films (IV) and a decrease in bacterial adhesion on modified mustard films (I); (e) nanodiamond modified chemically with hydroxyl functional groups $(\mathrm{MDCHPOH})$ coated laminates: an increase in bacterial adhesion was observed on modified ketchup films (III) and a decrease in bacterial 
adhesion on modified ice cream films (II); (f) nanodiamond particles manufactured by detonation method (DND) coated laminates: an increase in bacterial adhesion was observed on modified ice cream films (II) and a decrease in bacterial adhesion on modified coffee films (IV).
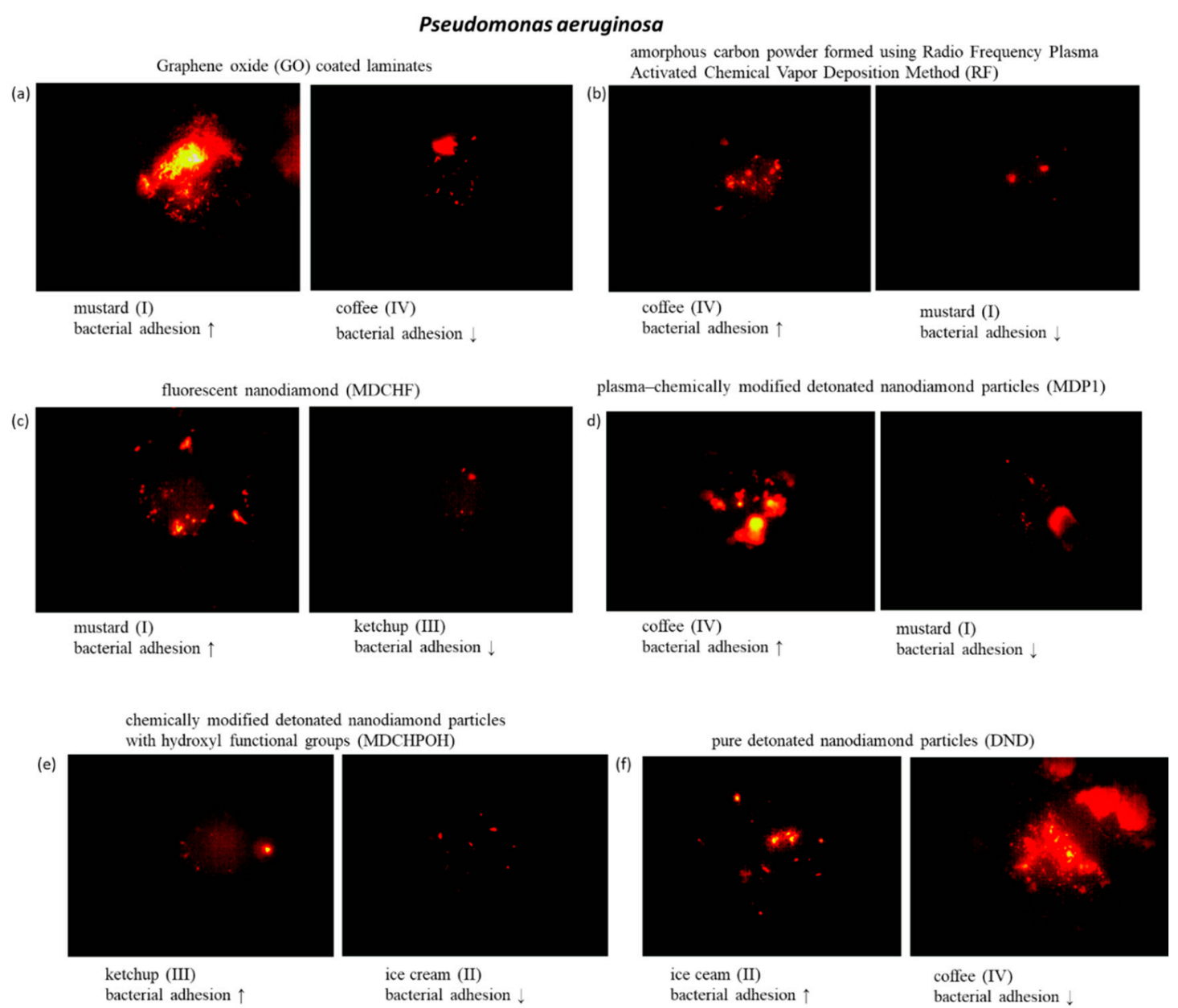

Figure 15. Images of Pseudomonas aeruginosa adhesion to laminates for food films I-mustard, II—ice cream, III—ketchup, IV—coffee, with the lowest and highest adhesion to layers formed by: (a) Graphene Oxide (GO) film; (b) amorphous carbon powder formed using Radio Frequency Plasma Activated Chemical Vapor Deposition Method (RF); (c) fluorescent nanodiamond (MDCHF); (d) plasma-chemically modified detonated nanodiamond particles (MDP1); (e) chemically modified detonated nanodiamond particles with hydroxyl functional groups $(\mathrm{MDCHPOH}) ;(\mathbf{f})$ pure detonated nanodiamond particles (DND).

The characteristics of the adhesion capacity of Escherichia coli to food packaging films (Figure 16) modified with carbon nanomaterials is as follows: (a) graphene oxide (GO) coated laminates: an increase in bacterial adhesion was observed on modified mustard films (I) and a decrease in bacterial adhesion on modified coffee films (IV); (b) an amorphous carbon powder formed using Radio Frequency Plasma Activated Chemical Vapor Deposition Method (RF) coated laminates: an increase in bacterial adhesion was observed on modified ketchup films (III) and a decrease in bacterial adhesion on modified coffee films (IV); (c) fluorescent detonation nanodiamond modified by rhodamine (MDCHF) coated laminates: an increase in bacterial adhesion was observed on modified ice cream films (II) and a decrease in bacterial adhesion on modified mustard films (I); (d) plasma-chemically modified detonated nanodiamond particles (MDP1) coated laminates: an increase in bacterial adhesion was observed on modified ice cream films (II) and a decrease in bacterial adhesion on modified mustard films (I); (e) nanodiamond modified chemically with hydroxyl functional groups (MDCHPOH) coated laminates: an increase in bacterial adhesion 
was observed on modified ice cream films (II) and a decrease in bacterial adhesion on modified ketchup films (III); (f) nanodiamond particles manufactured by detonation method (DND) coated laminates: an increase in bacterial adhesion was observed on modified ice cream films (II) and a decrease in bacterial adhesion on modified mustard films (I).

The evaluation of adhesion showed statistically significant differences in the effect of reducing adhesion and bacterial viability. Based on the study of bacterial adhesion to food packaging modified with nanomaterials, it was possible to determine the percentage of live bacteria in the adhesive layer (Figure 17). Living cells were manually counted under the microscope for all cells. Films without pathogens were used as controls.

\section{Escherichia coli}

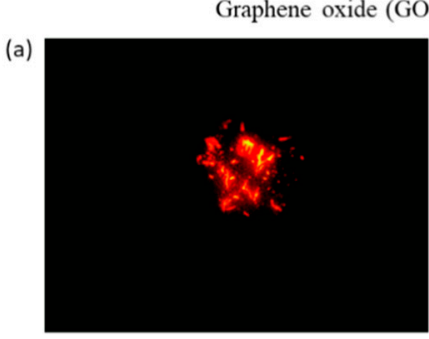

mustard (I) bacterial adhesion $\uparrow$

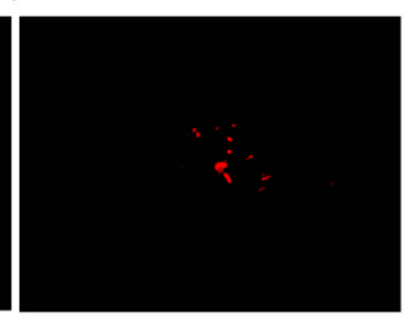

coffee (IV)

bacterial adhesion $\downarrow$

fluorescent nanodiamond (MDCHF)

(c)

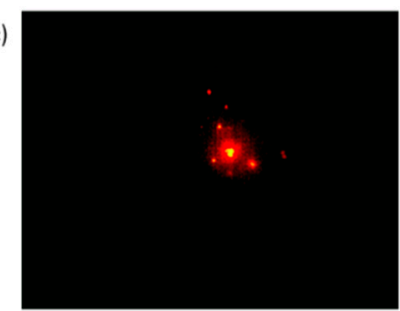

ice cream (II) bacterial adhesion $\uparrow$

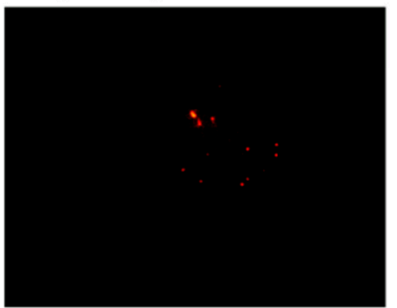

mustard (I) bacterial adhesion $\downarrow$

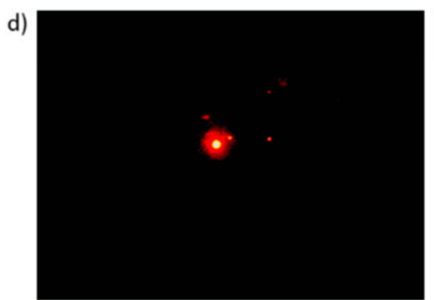

ice cream (II) bacterial adhesion $\uparrow$

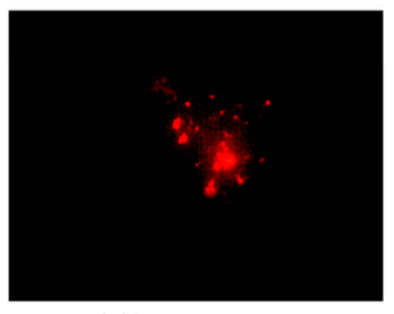

mustard (I) bacterial adhesion

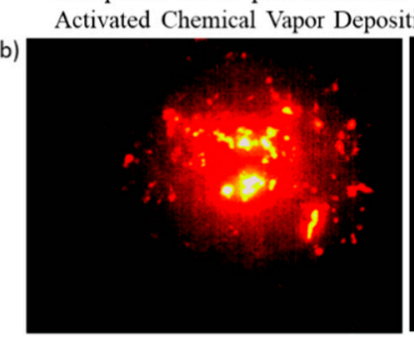

ketchup (III)

bacterial adhesion $\uparrow$ coffee (IV)

bacterial adhesion $\downarrow$

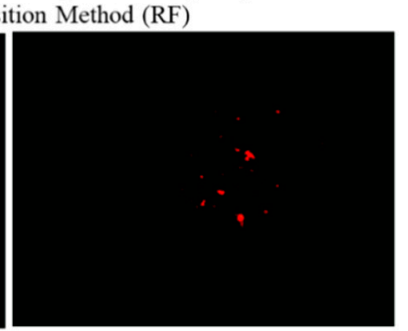

chemically modified detonated nanodiamond particles with hydroxyl functional groups (MDCHPOH)

(e)

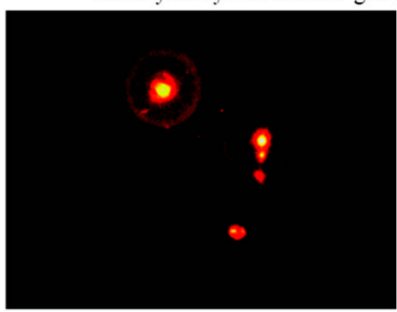

ice ceam (II) bacterial adhesion $\uparrow$

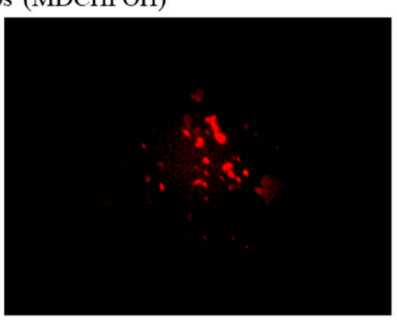

ketchup (III) bacterial adhesion

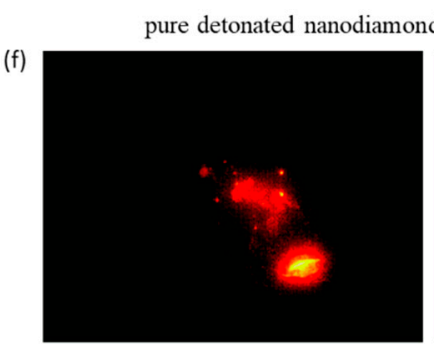

ice ceam (II) bacterial adhesion $\uparrow$

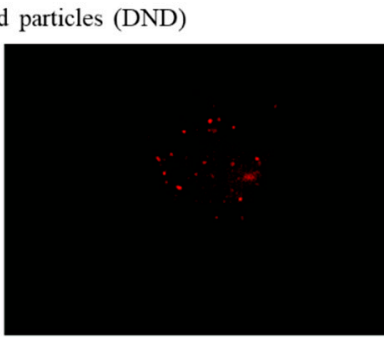

mustard (I)

bacterial adhesion

Figure 16. Images of Escherichia coli adhesion to laminates food I—mustard, II—ice cream, III—ketchup, IV—coffee, with the lowest and highest adhesion to layers formed by: (a) Graphene Oxide (GO) film; (b) amorphous carbon powder formed using Radio Frequency Plasma Activated Chemical Vapor Deposition Method (RF); (c) fluorescent nanodiamond (MDCHF); (d) plasma-chemically modified detonated nanodiamond particles (MDP1); (e) chemically modified detonated nanodiamond particles with hydroxyl functional groups (MDCHPOH); (f) pure detonated nanodiamond particles (DND). 
(a)

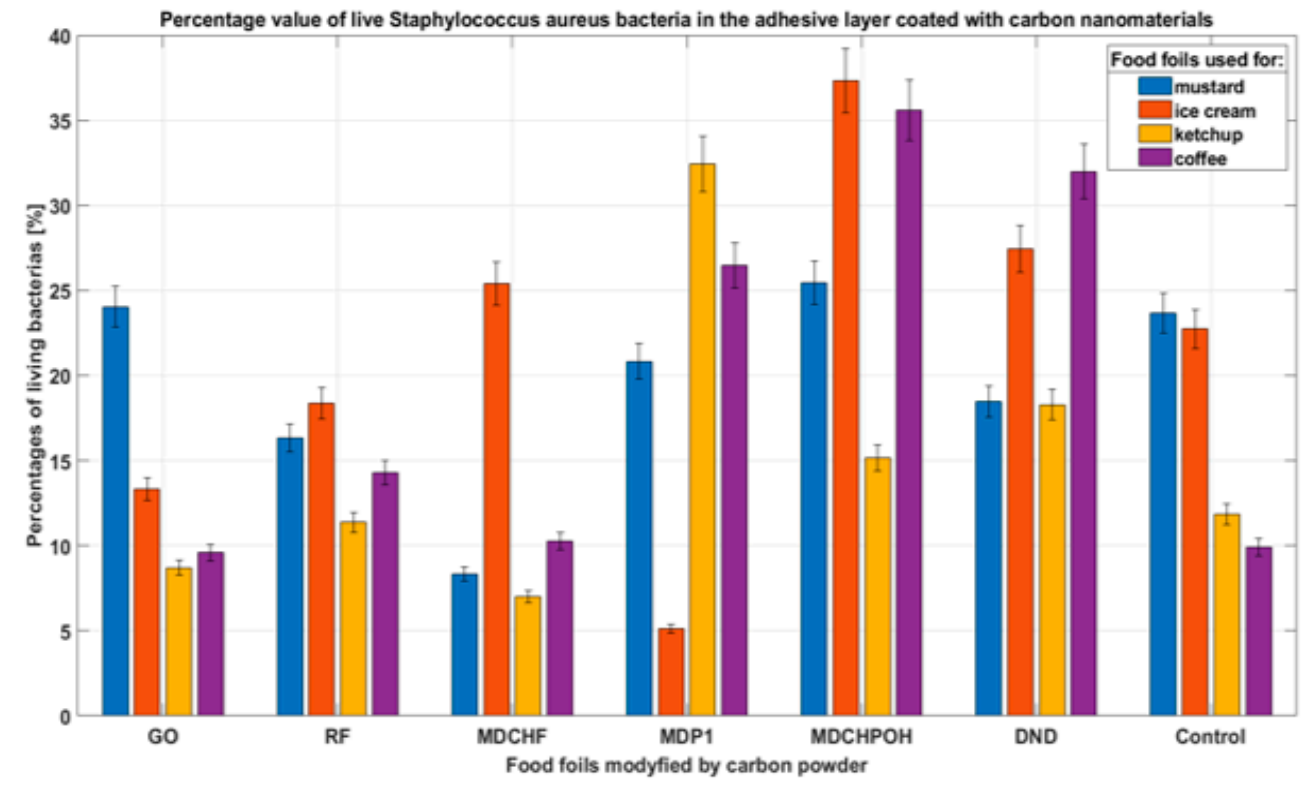

(b)

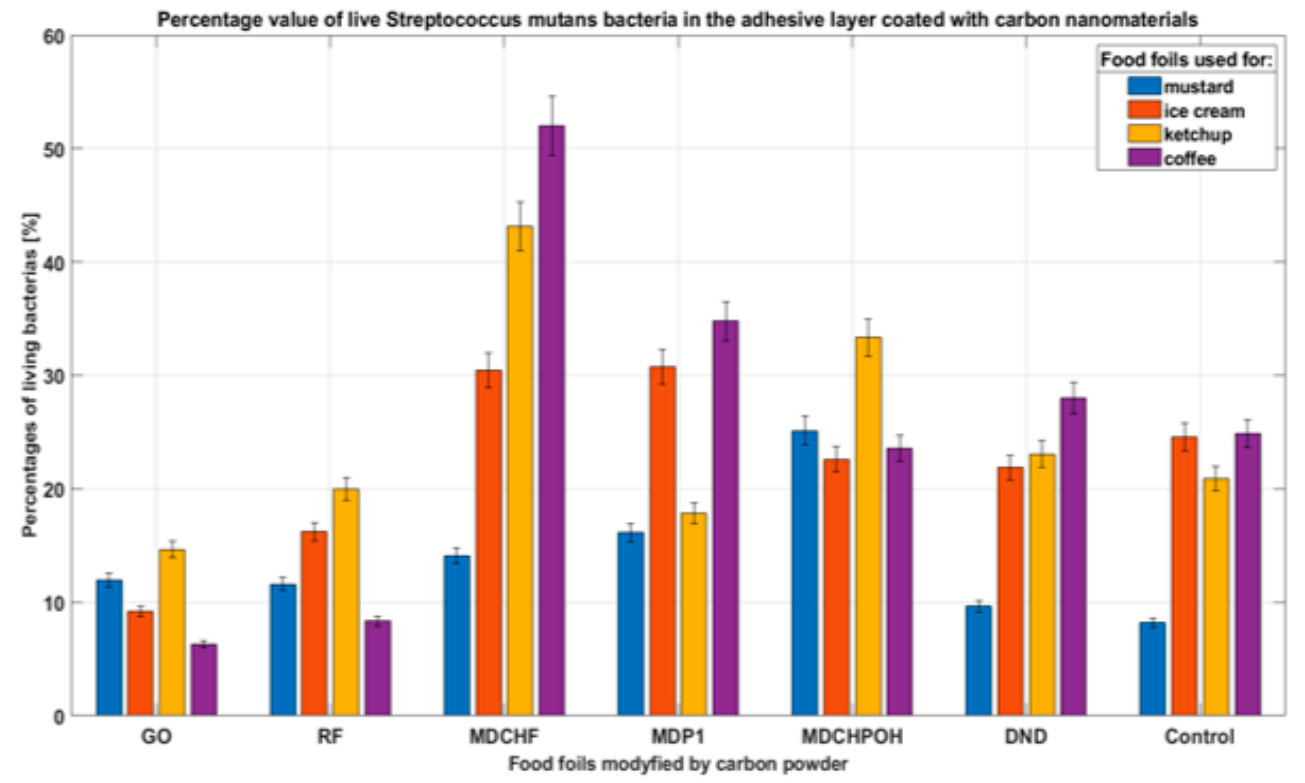

Figure 17. Cont. 
(c)

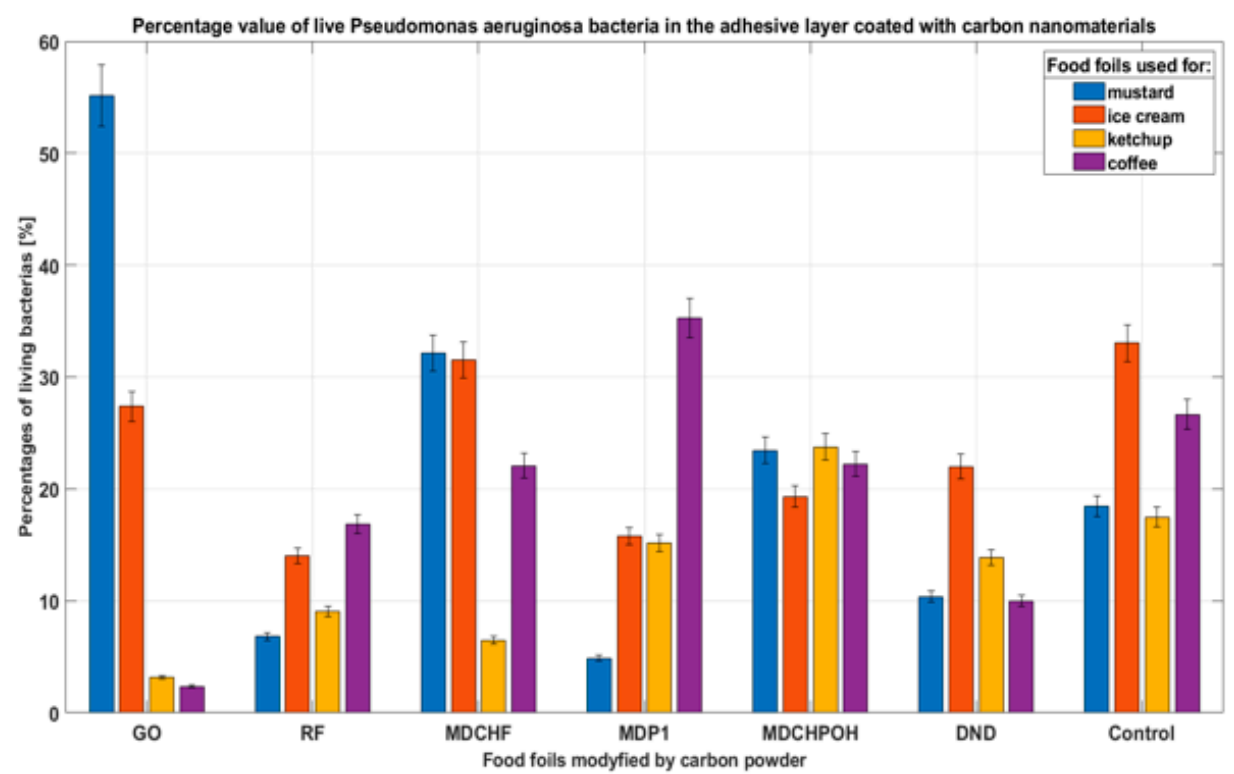

(d)

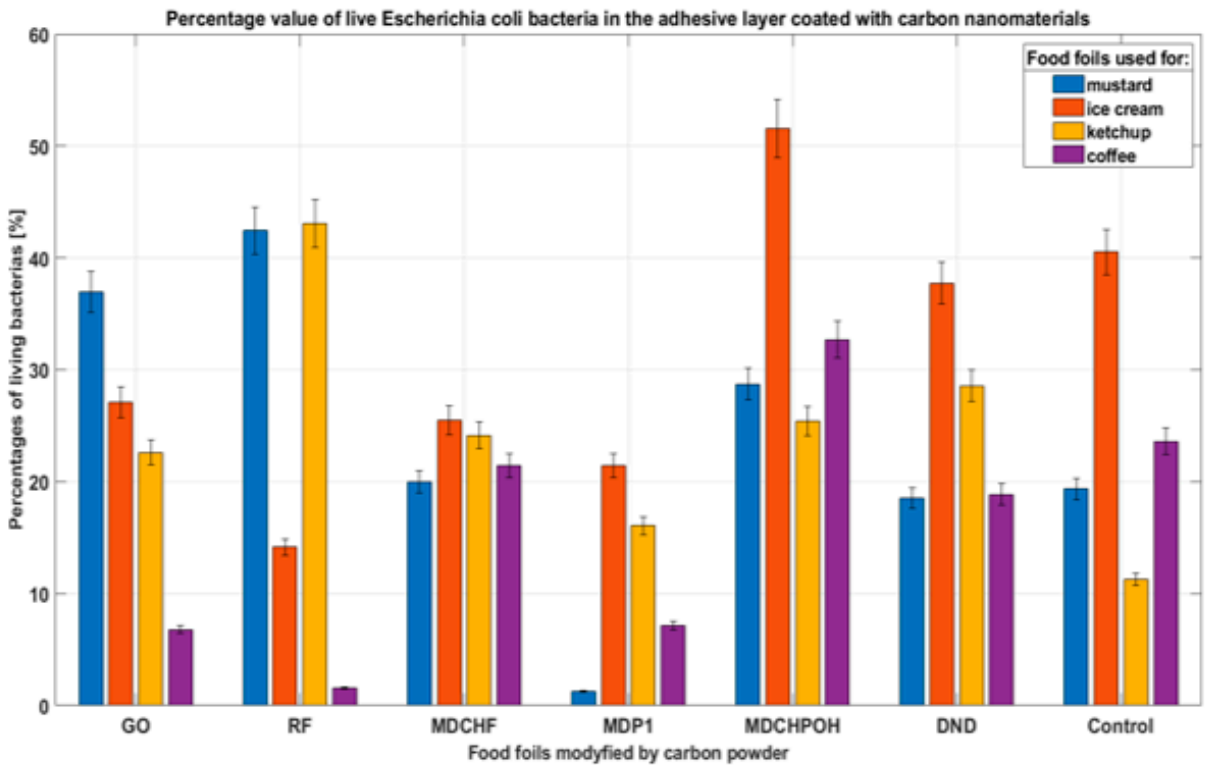

Figure 17. Assessment of the percentage of live bacteria in the adhesive layer. The analysis was carried out in terms of the type of bacteria (Staphylococcus aureus (a), Streptococcus mutans (b), Pseudomonas aeruginosa (c), Escherichia coli (d)). The bacteria interacted with carbon powders (GO, RF, MDCHF, MDP1, MDCHPOH, DND) on various types of film (I-mustard, II—ice cream, III-ketchup, IV—coffee).

Based on the data presented in Figure 16, it can be stated that the adhesion of Staphylococcus aureus to food packaging films modified with nanomaterials was the lowest in the case of films modified with graphene oxide. Only in the case of mustard film, the percentage of living pathogen was around $25 \%$. The pool of materials preventing the adhesion of Staphylococcus aureus also includes films modified by amorphous carbon 
powder formed using Radio Frequency Plasma Activated Chemical Vapor Deposition Method (RF). Similar results were seen in studies of the adhesion of Streptococcus mutans to four different food packaging materials (Figure 17b). In the case of films modified with graphene oxide, the content of live pathogens was the lowest among all tested materials. The most abundant amount of live Streptococcus mutans in the adhesive layer was found for packaging films modified with nanodiamonds containing rhodamine $\mathrm{B}$ residues on the surface (MDCHF). A different image of adhesion to food packaging films modified with nanomaterials was found for Pseudomonas aeruginosa (Figure 17c). In the pool of packaging materials modified with graphene oxide, low adhesion ability and low content of live pathogens were observed only for film III (ketchup) and film IV (coffee). Interestingly, in the case of all nanodiamond-based nanomaterials, a moderately low adhesion capacity of this pathogen and a relatively low number of identified viable bacterial cells were observed. In the test of adhesion of Escherichia coli to food packaging materials modified with nanomaterials (Figure 17d), satisfactory properties of film for food packaging modified with pure (unmodified) detonation nanodiamond particles as well as modified derivatives of nanodiamond particles were found. Interestingly, also in the case of this pathogen, the advantages of packaging materials modified with graphene oxide were not observed. However, when trying to generalize the results presented in Figure 17, it can be concluded that food films with incorporated nanodiamonds do not exhibit strong bactericidal or anti-adhesive properties onto polymer food films.

\section{Conclusions}

The carbon-based nanomaterials (CBN has many applications in medicine, cosmetology and the food industry. Using a scanning electron microscope and confocal microscope the topography of carbon was studied. The results of Raman spectroscopy confirm that the nanodiamond particles with surface modification show the highest content of the diamond phase, although the pure detonation powder has a higher ID/IG ratio compared to powder modified with hydroxyl groups. Single grain sizes of the powders tested by DLS method showed that the plasma-chemically modified powder has the highest activity of the reaction surface correlated with one of the smallest sizes of a single grain and with a very high content of diamond phase in Raman spectroscopy. The plasma-chemically modified powder shows the smallest size of conglomerates (in the SEM image) which correlates with one of the smallest sizes of a single grain and one of the largest content of diamond phase in Raman spectroscopy.

Our research shows, that electrokinetic potential is not the main indicator of bindings between surface and bacteria. In the case of Pseudomonas aeruginosa, positive effects in almost the whole spectrum of samples were obtained. Regardless of the type of bacteria, noticeable as well are the effects of creating carbon-based nanomaterials film formation on monolayer food films, 18 from 24 samples revealed a decrease in bacterial adhesion. Modified duplex and quadroplex food films allow bacteria to propagate more freely. The best antiadhesion properties were obtained on RF and GO film formation (10 samples with decreased properties, 4 with increased properties, and 2 with no influence on bacterial adhesion).

After testing the samples and comparing them with the control group, the greatest decrease in adhesion was observed on modified graphene oxide (GO) coffee film (less live bacteria in the field of vision for Pseudomonas aeruginosa and Streptococcus mutans), on modified plasma-chemically (MDP1) ice cream film for Staphylococcus aureus and on modified plasma-chemically (MDP1) mustard film for Escherichia coli. The greatest increase in adhesion (live bacteria in the field of vision) after testing the samples and comparing them with the control group and other carbon nanostructures was observed in: the ice cream film chemically modified with hydroxyl functional groups (MDCHPOH) for Staphylococcus aureus; the coffee film modified by fluorescent nanodiamond(MDCHF) for Streptococcus mutans; the mustard film modified by graphene oxide film (GO) for Pseudomonas aeruginosa and the ice cream chemically modified (MDCHPOH) with hydroxyl functional groups for Escherichia coli. The obtained results indicate a differentiation of bactericidal properties 
depending on the type of modification of nanodiamond particles and allotropic form of carbon. After the adhesion tests we can confirm our thesis that food films modified with carbon nanomaterials can affect the viability of bacteria. In addition, they initially exhibit bactericidal properties on the surfaces of commercial films used in the food industry.

Author Contributions: K.M.—conceptualization, formal analysis, project administration, resources; J.K. (Joanna Kornacka) — data curation, formal analysis, methodology, writing—original draft; E.K.data curation, methodology, resources, writing-review \& editing; J.K. (Jacek Kalisz)—data curation, methodology, writing—review \& editing; E.C.—methodology; M.A.—methodology; W.K.writing—review \& editing; B.K.—-methodology, writing—review \& editing; J.F.-methodology; T.B.—-methodology, writing-review \& editing; L.S.—methodology, P.L.—writing-review \& editing. All authors have read and agreed to the published version of the manuscript.

Funding: The authors are thankful for the financial support from Technical University of Liberec, Faculty of Mechanical Engineering with the support of the Institutional Endowment for the Long Term Conceptual Development of Research Institutes, as provided by the Ministry of Education, Youth and Sports of the Czech Republic in the year 2020.

Institutional Review Board Statement: Not applicable.

Informed Consent Statement: Not applicable.

Data Availability Statement: Not applicable.

Acknowledgments: The use of X'Pert Panalytical powder diffractometer (Malvern Panalytical, Malvern, UK). The authors gratefully acknowledge MSc Katarzyna Mydłowska (Koszalin University of Technology) for the help in taking the measurement and description of source files.

Conflicts of Interest: The authors declare no conflict of interest.

\section{References}

1. Danilenko, V.V. Nanodiamonds: Problems and prospects. J. Superhard Matter. 2010, 32, 301-310. [CrossRef]

2. Mitura, K.; Wyrebski, K.; Zarzycki, P.K. Bioactive food packaging with nanodiamond particles manufactured by detonation and plasma-chemical methods. In Food Packaging, 1st ed.; Grumezescu, A.M., Ed.; Elsevier: Amsterdam, The Netherlands, 2017; Volume 7, pp. 295-328.

3. Mitura, K.; Włodarczyk, E. Fluorescent nanodiamonds in biomedical applications. J. AOAC 2018, 101, 1-11. [CrossRef] [PubMed]

4. Mitura, K.; Zarzycki, P.K. Biocompatibiliy and toxicity of allotropic forms of carbon in food packaging. In Food Materials Science, 2nd ed.; Grumezescu, A.M., Holban, A.M., Eds.; Academic Press: Cambridge, MA, USA, 2018; Volume 19, pp. 73-102.

5. Zarzycki, P.K.; Świderska-Dabrowska, R.; Piaskowski, K.; Lewandowska, L.; Fenert, B.; Mitura, K.A.; Baran, J.M. Carbon and related nanomaterials as active media for analytical, biomedical and wastewater processing applications. In Pure and Functionalized Carbon-Based Nanomaterials, Analytical, Biomedical, Civil and Environmental Engineering Applications, 1 st ed.; Zarzycki, P.K., Ed.; CRC Press: Boca Raton, FL, USA; Taylor\&Francis Group: Oxfordshire, UK, 2020. [CrossRef]

6. Mitura, K.; Gisterek, I.; Ceynowa, P.; Wachowicz, A.; Pich, G.; Woś, R.; Adach, K. Badania mikrobiologiczne bioaktywnych proszków nanodiamentowych modyfikowanych chemicznie. In Postępy inżynierii biomedycznej; Leniowska, L., Nawrat, Z., Eds.; Wydawnictwo Uniwersytetu Rzeszowskiego: Rzeszów, Polska, 2013; pp. 157-167.

7. Shenderova, O.A.; McGuire, G. Nanomaterials Handbook; Gogotsi, Y., Ed.; CRC Press: Boca Raton, FL, USA, 2006 ; pp. $203-237$.

8. Zarzycki, P.K. Detection and Analysis of Microbes, Bioanalytes, and Micropollutants, Focusing on Food and Environmental Samples, Using Nanoparticle-Based Detection Systems, Microfluidic Analytical Devices, and Related Techniques. J. AOAC 2017, 100, 893-894. [CrossRef] [PubMed]

9. Prasek, M.; Sawosz, E.; Jaworski, S. Influence of nanoparticles of platinum on chicken embryo development and brain morphology. Nanoscale Res. Lett. 2013, 8, 251-260. [CrossRef] [PubMed]

10. Chwalibóg, A.; Sawosz, E.; Hotowy, A.; Szeliga, J.; Mitura, S.; Mitura, K.; Grodzik, M.; Orłowski, P.; Sokołowska, A. Visualization of interaction between inorganic nanoparticles and bacteria or fungi. Int. J. Nanomed. 2010, 5, 1085-1094. [CrossRef]

11. Sawosz, E.; Chwalibóg, A.; Mitura, K.; Mitura, S.; Szeliga, J.; Niemiec, T.; Rupiewicz, M.; Grodzik, M.; Sokołowska, A. Visualisation of morphological interaction of diamond and silver nanoparticles with Salmonella Enteritidis and Listeria monocytogenes. J. Nanosci. Nanotechnol. 2011, 11, 1-7. [CrossRef]

12. Kurantowicz, N.; Sawosz, E.; Jaworski, S.; Kutwin, M.; Strojny, B.; Wierzbicki, M.; Szeliga, J.; Hotowy, A.; Lipinska, L.; Kozinski, R.; et al. Interaction of graphene family materials with Listeria monocytogenes and Salmonella enterica. Nanoscale Res. Lett. 2015, 10, 1-12. [CrossRef]

13. Sawosz, E.; Jaworski, S.; Kutwin, M.; Hotowy, A.; Wierzbicki, M.; Grodzik, M.; Kurantowicz, N.; Strojny, B.; Lipinska, L.; Chwalibóg, A. Toxicity of pristine graphene in experiments in a chicken embryo model. Int. J. Nanomed. 2014, 9, 3913-3922. 
14. Jaworski, S.; Sawosz, E.; Kutwin, M.; Wierzbicki, M.; Hinzman, M.; Grodzik, M.; Winnicka, A.; Lipinska, L.; Włodyga, K.; Chwalibog, A. In vitro and in vivo effects of graphene oxide and reduced graphene oxide on glioblastoma. Int. J. Nanomed. 2015, 10, 1585-1596.

15. Epperla, C.P.; Mohan, N.; Chang, C.-W.; Chen, C.-C.; Chang, H.-C. Nanodiamond-Mediated Intercellular Transport of Proteins through Membrane Tunneling Nanotubes. Small 2015, 11, 6097-6105. [CrossRef] [PubMed]

16. Beveratos, A.; Kühn, S.; Brouri, R.; Gacoin, T.; Poizat, J.-P.; Grangier, P. Room temperature stable single-photon source. Eur. Phys. J. D 2002, 18, 191-196. [CrossRef]

17. Lien, Z.-Y.; Hsu, T.-C.; Liu, K.-K.; Liao, W.-S.; Hwang, K.-C.; Chao, J.-I. Cancer cell labeling and tracking using fluorescent and magnetic nanodiamond. Biomaterials 2012, 33, 6172-6185. [CrossRef] [PubMed]

18. Neburkova, J.; Vavra, J.; Cigler, P. Coating nanodiamonds with biocompatible shells for applications in biology and medicine. Curr. Opin. Solid State Mater. Sci. 2017, 21, 43-53. [CrossRef]

19. Shimoni, O.; Shi, B.; Adlard, P.A.; Bush, A.I. Delivery of Fluorescent Nanoparticles to the Brain. J. Mol. Neurosci. 2016, 60, 405-409. [CrossRef] [PubMed]

20. Zhang, X.Q.; Lam, R.; Xu, X.; Chow, E.K.; Kim, H.J.; Ho, D. Multimodal Nanodiamond Drug Delivery Carriers for Selective Targeting, Imaging, and Enhanced Chemotherapeutic Efficacy. Adv. Mater. 2011, 23, 4770-4775. [CrossRef]

21. Fu, C.-C.; Lee, H.-Y.; Chen, K.; Lim, T.-S.; Wu, H.-Y.; Lin, P.-K.; Wei, P.-K.; Tsao, P.-H.; Chang, H.-C.; Fann, W. Characterization and application of single fluorescent nanodiamonds as cellular biomarkers. Proc. Natl. Acad. Sci. USA 2007, 104, 727-732. [CrossRef]

22. Lin, H.-H.; Lee, H.-W.; Lin, R.-J.; Huang, C.-W.; Liao, Y.-C.; Chen, Y.-T.; Fang, J.-M.; Lee, T.-C.; Yu, A.-L.; Chang, H.-C. Tracking and Finding Slow-Proliferating/Quiescent Cancer Stem Cells with Fluorescent Nanodiamonds. Small 2015, 11, 4394-4402. [CrossRef]

23. Slegerova, J.; Hajek, M.; Rehor, I.; Sedlak, F.; Stursa, J.; Hruby, M.; Cigler, P. Designing the nanobiointerface of fluorescent nanodiamonds: Highly selective targeting of glioma cancer cells. Nanoscale 2015, 7, 415-420. [CrossRef]

24. Cushena, M.; Kerryb, J.; Morrisc, M.; Cruz-Romeroband, M.; Cumminsa, E. Nanotechnologies in the food industry: Recent, developments, risks and regulation. Trends Food Sci. Technol. 2012, 24, 30-46. [CrossRef]

25. Mihranyan, A.; Ferraz, N.; Strømme, M. Current status and future prospects of nanotechnology in cosmetics. Prog. Mater. Sci. 2012, 57, 875-910. [CrossRef]

26. Rossi, M.; Cubaddac, F.; Dinid, L.; Terranovae, M.L.; Aurelic, F.; Sorbof, A.; Passeri, D. Scientific basic of nanotechnology, implications for the food sector and future trends. Trends Food Sci. Technol. 2014, 40, 127-148. [CrossRef]

27. Quintavalla, S.; Vicini, L. Antimicrobial food packaging in the meat industry. Meat Sci. 2002, 62, 373-380. [CrossRef]

28. Limbo, S.; Khaneghah, A.M. Active packaging of foods and its combination with electron beam processing. In Electron Beam Pasteurization and Complementary Food Processing Technologies; Pillai, S., Shayanfar, S., Eds.; Woodhead Publishing: Sawston, UK, 2015; Volume 11, pp. 195-217.

29. Khaneghaha, A.M.; Hashemi, S.M.B.; Limbo, S. Antimicrobial agents and packaging systems in antimicrobial active food packaging: An overview of approaches and interactions. Food Bioprod. Process. 2018, 111, 1-19. [CrossRef]

30. Bajpai, V.K.; Kamle, M.; Shukla, S.; Mahato, D.K.; Chandra, P.; Hwang, S.K.; Kumar, P.; Huh, Y.S.; Han, Y.-K. Prospects of using nanotechnology for food preservation, safety, and security. J. Food Drug Anal. 2018, 26, 1201-1204. [CrossRef] [PubMed]

31. Kalpana, S.; Priyadarshini, S.R.; Maria Leena, M.; Moses, J.A.; Anandharamakrishnan, C. Intelligent packaging: Trends and applications in food systems. Trends Food Sci. Technol. 2019, 93, 145-157. [CrossRef]

32. Sothornvit, R. Nanostructured materials for food packaging systems: New functional properties. Curr. Opin. Food Sci. 2019, 25, 82-87. [CrossRef]

33. Sozer, N.; Kokini, J.L. Nanotechnology and its applications in food sector. Trends Biotechnol. 2009, 27, 82-89. [CrossRef]

34. Majid, I.; Ahmad Nayik, G.; Mohammad Dar, S.; Nanda, V. Novel food packaging technologies: Innovations and future prospective. J. Saudi Soc. Agric. Sci. 2016, 17, 454-462. [CrossRef]

35. Missaoui, W.N.; Arnold, R.D.; Cummings, B.S. Toxicological status of nanoparticles: What we know and what we don't know. Chem. Biol. Interact. 2018, 295, 1-2. [CrossRef]

36. Youssef, A.M.; El-Sayed, S.M. Bionanocomposites materials for food packaging applications: Concepts and future outlook. Carbohyd. Polym. 2018, 193, 19-27. [CrossRef]

37. Garcia, C.V.; Shin, G.H.; Kim, J.T. Metal oxide-based nanocomposites in food packaging: Applications, migration, and regulations. Trends Food Sci. Technol. 2018, 82, 21-31. [CrossRef]

38. Abreu, A.S.; Oliveira, M.; de Sá, A.; Rodrigues, R.M.; Cerqueira, M.A.; Vicente, A.A.; Machado, A.V. Antimicrobial nanostructured starch based films for packaging. Carbohyd. Polym. 2015, 129, 127-134. [CrossRef] [PubMed]

39. De Azeredo, H.M.C. Antimicrobial nanostructures in food packaging. Trends Food Sci. Technol. 2013, 30, 56-69. [CrossRef]

40. Fabra, M.J.; Busolo, M.A.; Lopez-Rubio, A.; Lagaron, J.M. Nanostructured biolayers in food packaging. Trends Food Sci. Technol. 2013, 31, 79-87. [CrossRef]

41. Bridier, A.; Sanchez-Vizuete, P.; Guilbaud, M.; Piard, J.C.; Naïtali, M.; Briandet, R. Biofilm-associated persistence of food-borne pathogens. Food Microbiol. 2015, 45, 167-178. [CrossRef] [PubMed]

42. Vilela, C.; Kurek, M.; Hayouka, Z.; Röcker, B.; Yildirim, S.; Antunes, M.D.C.; Freire, C.S.R. A concise guide to active agents for active food packaging. Trends Food Sci. Technol. 2018, 80, 212-222. [CrossRef]

43. Marinello, F.; La Storia, A.; Mauriello, G.; Passeri, D. Atomic Force Micrscopy techniques to investigate activated food packaging materials. Trends Food Sci. Technol. 2018, 87, 84-93. [CrossRef] 
44. Guo, X.; Mei, N. Assessment of the toxic potential of graphene family nanomaterials. J. Food Drug Anal. 2014, 22, 105-115. [CrossRef] [PubMed]

45. He, X.; Hwang, H.M. Nanotechnology in food science: Functionality, applicability, and safety assessment. J. Food Drug Anal. 2016, 24, 671-681. [CrossRef] [PubMed]

46. Pathakoti, K.; Manubolu, M.; Hwang, H.-M. Nanostructures: Current uses and future applications in food science. J. Food Drug Anal. 2017, 25, 245-253. [CrossRef]

47. Donglu, F.; Wenjian, Y.; Kimatu, B.M.; Mariga, A.M.; Liyan, Z.; Xinxin, A.; Qiuhui, H. Effect of nanocomposite-based packaging on storage stability of mushrooms (Flammulina velutipes). Innov. Food Sci. Emerg. 2016, 33, 489-497. [CrossRef]

48. Dudefoi, W.; Villares, A.; Peyron, S.; Moreau, C.; Ropers, M.H.; Gontard, N.; Cathala, B. Nanoscience and nanotechnologies for biobased materials, packaging and food applications: New opportunities and concerns. Innov. Food Sci. Emerg. 2018, 46, 107-121. [CrossRef]

49. Maas, M. Carbon Nanomaterials as Antibacterial Colloids. Materials 2016, 9, 617. [CrossRef] [PubMed]

50. Szunerits, S.; Barras, A.; Boukherroub, R. Antibacterial Applications of Nanodiamonds. Int. J. Environ. Res. Public Health 2016, 13, 413. [CrossRef] [PubMed]

51. Schrand, A.M.; Huang, H.; Carlson, C.; Schlager, J.J.; Osawa, E.; Hussain, S.M.; Dai, L. Are diamond nanoparticles cytotoxic? J. Phys. Chem. B 2007, 111, 2-7. [CrossRef]

52. Wassowicz, M.; Ficek, M.; Wróbel, M.S.; Chakraborty, R.; Fixler, D.; Wierzba, P.; Jedrzejewska-Szczerska, M. Hemocompatibility of Modified Nanodiamonds. Materials 2017, 10, 352. [CrossRef] [PubMed]

53. Plotnikov, V.A.; Makarov, S.V.; Bogdanov, D.G.; Bogdanov, A.S. The structure of detonation nanodiamond particles. In Proceedings of the AIP Conference Proceedings, Yogyakarta, Indonesia, 25-26 January 2016; Volume 1785, pp. 040045-1-040045-4. [CrossRef]

54. Bakowicz-Mitura, K.; Bartosz, G.; Mitura, S. Influence of diamond powder particles on human gene expression. Surf. Coat. Technol. 2007, 201, 6131-6135. [CrossRef]

55. Solarska, K.; Gajewska, A.; Bartosz, G.; Mitura, K. Induction of apoptosis in human endothelial cells by nanodiamond particles. J. Nanosci. Nanotechnol. 2012, 12, 5117-5121. [CrossRef]

56. Gronwald, H.; Mitura, K.; Volesky, L.; Kejzlar, P.; Szczypinski, M.; Kubala, E.; Strzelecka, P.; Grzegocka, M.; Baszuk, P.; Skomro, P.; et al. The influence of suspension containing nanodiamonds on morphology of the tooth tissue in atomic force microscope observations. Biomed. Res. Int. 2018, 2018, 1-9. [CrossRef]

57. Peng, Z.; Liu, X.; Zhang, W.; Zeng, Z.; Liu, Z.; Zhang, C.; Liu, Y.; Shao, B.; Liang, Q.; Tang, W.; et al. Advances in the application, toxicity and degradation of carbon nanomaterials in environment: A review. Environ. Int. 2019, 134, 105298. [CrossRef]

58. Niemiec, T.; Szmidt, M.; Sawosz, E.; Grodzik, M.; Mitura, K. The effect of diamond nanoparticles on redox and immune parameters in rats. J. Nanosci. Nanotechnol. 2011, 11, 9072-9077. [CrossRef] [PubMed]

59. Eivazzadeh-Keihan, R.; Maleki, A.; de la Guardia, M.; Bani, M.S.; Chenab, K.K.; Pashazadeh-Panahi, P.; Baradaran, B.; Mokhtarzadeh, A.; Hamblin, M.R. Carbon based nanomaterials for tissue engineering of bone: Building new bone on small black scaffolds: A review. J. Adv. Res. 2019, 18, 185-201. [CrossRef] [PubMed]

60. Chauhan, S.; Jain, N.; Nagaich, U. Nanodiamonds with powerful ability for drug delivery and biomedicalapplications: Recent updates on in vivo study and patents. J. Pharm. Anal. 2020, 10, 1-12. [CrossRef] [PubMed]

61. Mitura, K.; Wilczek, P.; Niemiec-Cyganek, A.; Morenc, M.; Dudek, M.; Sobczyk-Guzenda, A.; Fraczyk, J.; Kolesińska, B. Detonation nanodiamond particles modified by non-steroidal anti-inflammatory drugs in vitro examination. Eng. Biomater. 2017, 20, 12-20.

62. Kolesinska, B.; Rozniakowski, K.K.; Fraczyk, J.; Relich, I.; Papini, A.M.; Kaminski, Z.J. The Effect of Counterion and Tertiary Amine on the Efficiency of N-Triazinylammonium Sulfonates in Solution and Solid-Phase Peptide Synthesis. Eur. J. Org. Chem. 2015, 2, 401-408. [CrossRef]

63. Fraczyk, J.; Walczak, M.; Szymanski, L.; Kolacinski, Z.; Wrzosek, H.; Majsterek, I.; Przybylowska-Sygut, K.; Kaminski, Z.J. Carbon nanotubes functionalized with folic acid attached via biomimetic peptide linker. Nanomedicine 2017, 12, 2161-2182. [CrossRef] [PubMed]

64. Fraczyk, J.; Rosowski, A.; Kolesinska, B.; Koperkiewcz, A.; Sobczyk-Guzenda, A.; Kaminski, Z.J.; Dudek, M. Orthogonal Functionalization of Nanodiamond Particles after Laser Modification and Treatment with Aromatic Amine Derivatives. Nanomaterials 2018, 8, 908. [CrossRef]

65. SN 195920-ASTM E2922. Textile Fabrics—Determination of the Antibacterial Activity-Agar Diffusion Plate Test. Available online: https:/ / standards.globalspec.com/std/906029/SN\%20195920 (accessed on 28 January 2021).

66. Mitura, K. HR TEM examinations of nanodiamond particles for biomedical application. J. Achiev. Mater. Manuf. Eng. 2009, 37, 317-322.

67. Bogdanov, D.; Plotnikova, V.; Bogdanov, A.; Makarov, S.; Vins, V.; Yelisseyev, A.; Lin, V.; Chepurov, A. Consolidation of nanocrystals of detonation diamonds at high-pressure high temperature sintering. Int. J. Refract. Hard Met. 2018, 71, 101-105. [CrossRef]

68. Krysthal, A.P.; Mchedlov-Petrossyan, N.O.; Laguta, A.N.; Kirklya, N.N.; Kruk, A.; Osawa, E. Primary detonation nanodiamond particles: Their core-shell structure and the behavior in organo-hydrosols. Colloids Surf. A Phys. Eng. Asp. 2020, 614, 126079. [CrossRef]

69. Mitura, S. Nucleation of diamond powder particles in an RF methane plasma. J. Cryst. Growth 1987, 80, 417-424. [CrossRef] 
70. Goottenbos, B.; Van der Mei, H.C.; Busscher, H.J. Initial adhesion and surface growth of Pseudomonas aeruginosa on negatively and positively charged poly(methacrylates). J. Mater. Sci. Mater. Med. 1999, 10, 853-855. [CrossRef] [PubMed]

71. Walker, S.L.; Hill, J.E.; Redman, J.A.; Elimelech, M. Influence of Growth Phase on Adhesion Kinetics of Escherichia coli D21g. Appl. Environ. Microbiol. 2005, 71, 3093-3099. [PubMed]

72. Sheng, X.; Peng Ting, Y.; Olavi Pehkonen, S. The influence of ionic strength, nutrients and $\mathrm{pH}$ on bacterial adhesion to metals. J. Colloid Interface Sci. 2008, 321, 256-264. [CrossRef] [PubMed] 